In Press, Educational Psychologist

Moving the Achievement Goal Approach One Step Forward:

Towards a Systematic Examination of the Autonomous and Controlled Reasons

Underlying Achievement Goals

\author{
Vansteenkiste, Maarten \\ University of Gent, Belgium \\ Lens, Willy \\ University of Leuven, Belgium \\ University of the Free State, South Africa \\ Elliot, Andrew J. \\ University of Rochester, USA \\ Soenens, Bart \\ University of Gent, Belgium \\ Mouratidis, Athanasios \\ Hacettepe University, Turkey
}

Corresponding author:

Maarten Vansteenkiste

Department of Developmental, Personality and Social Psycholgy

H. Dunantlaan 2

9000 Gent - Belgium

E-mail: Maarten.Vansteenkiste@ugent.be

Phone: 0032-9-2646413 


\begin{abstract}
An important recent development in the achievement goal literature is to define achievement goals strictly as aims. In this overview, we argue that this restrictive definition of achievement goals paves the way for a systematic consideration of the autonomous and controlled reasons underlying individuals' achievement goals, a distinction central to Self-Determination Theory. To stimulate work in this area, we formulated five propositions, arguing that consideration of the "why" (i.e., type of reasons) in addition to the "what" (i.e., type of aims) of achievement goals, (a) provides an account for the regulatory basis of achievement goals, (b) opens the door for other motivation theories to be linked to the achievement goal literature, (c) matters in terms of predicting outcomes, (d) allows for a richer account of contextual forces influencing motivation, and (e) sets the stage for an enriched hierarchical model of achievement motivation. In closing, we discuss various future research directions.
\end{abstract}

Key terms: Achievement goals, Reasons, Hierarchical Model of Achievement Motivation, Self-Determination Theory, Autonomous and Controlled Regulation 


\section{Moving the Achievement Goal Approach One Step Forward: \\ Towards a Systematic Examination of the Autonomous and Controlled Reasons Underlying Achievement Goals}

The literature on achievement goals has burgeoned over the past 30 years. By relying on cross-sectional, longitudinal, and experimental methodologies, scholars in diverse domains, including education, sport, and work, have documented the correlates and effects of different types of achievement goals (Elliot, 2005; Hulleman, Schrager, Bodmann, \& Harackiewicz, 2010; Kaplan \& Maehr, 2007; Murayama, Elliot, \& Friedman, 2011; Van Yperen, Blaga, \& Postmes, in press). The aim of the present contribution is to review recent empirical work that has just begun to systematically consider people's underlying reasons for adopting and pursuing achievement goals.

Although a variety of motivational taxonomies are available in the literature to conceptualize these underlying reasons (e.g., Dompnier, Darnon, \& Butera, 2009; Urdan \& Mestas, 2006), we choose to draw on Self-Determination Theory (SDT; Deci \& Ryan, 2000; Vansteenkiste, Niemiec, \& Soenens, 2010). SDT is a well-validated theory, which has a long tradition of examining the reasons underlying individuals' activity engagement and thus proved ideally suited to theorize about and examine the reasons underlying individuals' achievement goal pursuit. Within SDT, it is maintained that these reasons can vary in their level of autonomy and volition relative to control and pressure. When learners' achievement goal pursuit is controlled regulated, they feel pressured, either from the outside or from within, to pursue and attain particular achievement goals. Instead, when learners' achievement goal pursuit is autonomously regulated, they have either fully endorsed the goal or they experience the goal pursuit as inherently satisfying and challenging. To illustrate, when taking an entrance exam at the beginning of college, learners could feel pressured by their parents 
(i.e., controlled reason) to outperform their peers (i.e., performance-approach goal) or they could more willingly pursue the goal of doing better than their peers because they foresee the personal benefits of doing so (i.e., autonomous reason). Similarly, due to time constraints, learners could feel pressured (i.e., controlled reason) to fully understand the learning material at hand (i.e., mastery-approach goal) or they could focus on mastering the learning material out of a sense of intrinsic curiosity and interest (i.e., autonomous reason).

Throughout this contribution, we seek to make the case that consideration of these autonomous and controlled underlying reasons enables achievement goal researchers to take the achievement goal approach one step further. Indeed, this contribution could be construed as a call for achievement goal researchers to move beyond looking only at the strength of pursuing particular achievement goals to additionally consider the reasons underlying achievement goals. To achieve this aim, we have divided this article into three major sections. In the first section, we review three historical trends that characterize the more recent achievement goal literature; this also helps to clarify the incremental value and necessity of the current contribution. In the second section, we formulate five new propositions that aim to elucidate the added value of considering the reasons underlying achievement goal striving. Finally, in the last section, we lay out a number of future research directions in the interest of stimulating empirical work in this area.

\section{Part I: Historical Trends}

\section{Towards Extension: Increasing the Number of Achievement Goals}

One trend that can be clearly noted in the achievement goal literature involves the gradual extension of the number of studied achievement goals across the years, increasing from two (Dweck, 1986; Nicholls, 1984) to three (Elliot \& Harackiewicz, 1996) to four (Elliot, 1999), and most recently to six (Elliot, Murayama, \& Pekrun, 2011). Specifically, the dichotomous achievement goal perspective (e.g., Dweck \& Leggett, 1988; Nicholls, 1984) 
was limited to the examination of two achievement goals, that is, mastery goals (i.e., a focus on attaining task-based requirements or improvement) and performance goals (i.e., a focus on outperforming others or avoiding doing worse than others). Within, the trichotomous perspective, three different achievement goals were studied as the performance goal was bifurcated into performance-approach and performance-avoidance goals. These goals are oriented towards the attainment of normative competence (performance-approach) and the avoidance of normative incompetence (performance-avoidance; Elliot \& Harackiewicz, 1996; Skaalvik, 1997). For instance, learners could be focused on outperforming their peers on a test (i.e., performance-approach goals) or on avoiding worse test results than their peers (i.e., performance-avoidance goals; e.g., Matos, Lens, \& Vansteenkiste, 2007).

The next step then involved applying the valence dimension systematically across both performance and mastery goals, such that a 2x2 framework was developed (Elliot, 1999; Pintrich, 2000). Specifically, the valence dimension concerns whether competence is construed in a positive way (i.e., as approaching competence) or in a negative way (i.e., as avoiding incompetence). This dimension is crossed with the way competence and the resulting outcome is defined, that is, on the basis of normative versus task-based standards. Thus, a task-based standard can also be either approached, as when learners try to master the requirements of a task, or avoided, as when learners aim to avoid learning less than they possibly could.

Subsequent work within the $2 \times 2$ approach revealed that the mastery goal concept was operationalized in various ways. In most studies, individuals were said to be mastery oriented when they were striving to master the requirements of the task (e.g., Elliot \& McGregor, 2001); yet, some scholars also considered individuals' attempts to surpass an intrapersonal standard as an adequate operationalization of mastery goals (e.g., Van Yperen, 2006; see also Martin, 2006). The critical difference here involves the type of standard that individuals focus 
on, which could be either purely task-based or focused on individuals' intrapersonal standards. To illustrate, learners could be focused on acquiring a new math skill (i.e., taskbased criterion) or they could try to do better on a second math exam than they did on the first (i.e., intrapersonal criterion).

The next logical step involved breaking down this non-differentiated mastery goal construct such that a formal distinction was made between task-based and intrapersonal standards, which were both differentiated from normative standards (Elliot et al., 2011). As a result, a 3x2 model was proposed, which is graphically displayed in Figure 1. Within this model, individuals can focus on three different types of types of competence standards in achievement settings: task-based (i.e., how one is doing relative to inherent task demands), self-based (i.e., how one is doing relative to how one has done before) and other-based (i.e., how one is doing relative to others). Individuals can focus on attaining each of these standards or they can focus on avoiding to not attain them. To illustrate this dynamic for intrapersonal standards, runners could aim to improve their personal best time or they could focus on avoiding running slower than they did last season.

Although work on the $3 \times 2$ perspective is still in its infancy, this gradual extension of the number of achievement goals has proven fruitful. Overall, the steady increase in the number of achievement goals does not involve a loss of parsimony, as the added achievement goals are theoretically grounded and allow for a fuller explanation (i.e., accounting for more variance) of "old" outcomes, while simultaneously accounting for a broader set of phenomena. To illustrate, self-based goals have been found to yield a unique association with learners' energy in class (new outcome), while all three approach goals were predicted by approach temperament (Elliot et al., 2011; see Murayama et al., 2011 and Senko, et al., 2011 for recent narrative overviews). Different researchers use different terminology to refer to the various goals of the $3 \times 2$ model. From this point forward in our narrative, we use the following 
terms from the $3 \times 2$ model: task-approach, task-avoidance, self-approach, self-avoidance, other-approach, and other-avoidance; when referring to variables used in prior research, we continue to use the terminology used by those who conducted the research.

\section{Towards Integration: The Hierarchical Model of Achievement Motivation}

A second important evolution within the achievement goal literature represents the integration of the more recent work on achievement goals with the classic work on achievement-related motive dispositions (Atkinson, 1957). In the hierarchical model of achievement motivation (Elliot, 1999; Elliot \& Church, 1997), achievement-related motive dispositions represent broad competence-based constructs that influence the adoption of achievement goals in specific achievement situations. Two motivational dispositions in particular have received much research attention and are critical to the current review, that is, the need for achievement and fear of failure. As introduced by Atkinson (1957; see also McClelland, Atkinson, Clark, \& Lowell, 1953), need for achievement represents individuals' dispositional inclination to seek positive outcomes (i.e., success) in achievement tasks, whereas fear of failure represents individuals' dispositional tendency to avoid negative outcomes (i.e., failure) in such tasks. Within the hierarchical model of achievement motivation (Elliot, 1999), these acquired motive dispositions reflect general competence- and affect-based motivational constructs that energize individuals in achievement situations and orient them towards success or away from failure. Achievement goals thus represent the channels through which the motive to succeed and the motive to avoid failure manifest themselves in more specific achievement contexts or situations. For instance, individuals with a strong need for achievement might become focused on outperforming others (i.e., adopt an other-approach goal) in a specific achievement situation because they consider this as a possible route to meet their need for achievement. In contrast, individuals high in fear of 
failure might be more likely to adopt avoidance-based achievement goals, as such goals fit with their more general tendency to avoid mistakes and incompetence.

The inclusion of these antecedent motives is of considerable theoretical importance, because a full motivation theory needs to address both the direction as well as the energetic basis and instigation of human behavior (Deci \& Ryan, 1985; Elliot, 1997). That is, to provide a full account of individuals' motivational functioning, one needs to know not only where individuals are moving towards, but also why they are choosing a particular direction. Clearly, achievement goals themselves are indicative of the direction of individuals' functioning in a particular achievement situation. For instance, a student may be focused on doing better than she did before on her exams or a tennis player may be focused on outperforming her opponent during the game. Yet, these goals do not emerge from a vacuum. They need to be energized; that is, a source needs to be identified from which achievement goals emerge and are fuelled with energy. Consideration of the motive to succeed and the motive to avoid failure enabled achievement goal theorists to incorporate the energizing basis of goal-directed motivated action.

Previous work indicates that the need for achievement, as an appetitive form of motivation, is related to the adoption of mastery-approach goals, whereas fear of failure, as an avoidance form of motivation, is related to performance-avoidance goals (Elliot \& Church, 1997; Tanaka \& Yamauchi, 2001). Interestingly, and in contrast to Atkinson's original view that fear of failure is inhibitory (Atkinson \& Feather, 1966), both the need for achievement and fear of failure have been found to relate to performance-approach goals, suggesting that performance-approach goals can be instigated by different distal motivational dispositions (Elliot \& Church, 1997). Subsequent studies incorporating more sophisticated statistical analyses (e.g., Elliot \& Murayama, 2008; Zusho, Pintrich, \& Cortina, 2005) have replicated this pattern of relations. 


\section{Towards Conceptual Precision: Detaching Reasons from Aims}

A third and less visible evolution in the achievement goal literature involves the movement towards greater conceptual precision. This change gets at the heart of the achievement goal construct itself, as the change is definitional in nature. Specifically, Elliot and his collaborators (Elliot, 1999; Elliot \& Thrash, 2001; Elliot \& Murayama, 2008) have proposed a shift in the definition of achievement goals, arguing in favor of a narrower definition of the goal concept. This change implies an important deviation from the theorizing and empirical work of the founders of the achievement goal construct. Although coming from different backgrounds, Dweck and Nicholls adopted the same relatively broad definition of achievement goals, also labeled achievement goal orientation (Ames, 1992; Dweck, 1986; Nicholls, 1984). From their viewpoint, an achievement goal consisted of an agglomeration of different, yet related competence-based processes, including aims, reasons, feelings, and, in some cases, even attributions (see Ames \& Archer, 1987). Stated differently, achievement goals were conceived of as omnibus constructs (Murayama et al., 2011).

To illustrate this broad view on achievement goals, when performance-oriented, one tends to focus on outperforming others to demonstrate one's ability, to show one's worth, and to validate one's ego. This goal would be best achieved when the "maximin principle" is respected, that is, when one is capable of garnering a maximum of results within a minimum amount of time and with a minimum of effort-expenditure. Further, when facing failure, performance-oriented individuals are said to protect their ego by attributing the failure to external factors (Nicholls, 1984). In contrast, when mastery-oriented, one is focused on developing one's competence. For a person who is striving for improvement, mastering the requirements of the task at hand and effort-expenditure is perceived as integral to one's goal pursuit (Dweck \& Leggett, 1988; Nicholls, 1984). Failure is not a problem, as any mistakes are perceived as informational, that is, as contributing to a better mastering of the task at hand. 
A central emphasis in a mastery orientation is that competence development is expressed through curiosity and challenge seeking, as one is curious to learn and wants to be challenged to master the material at hand.

As these illustrative descriptions suggest, when achievement goals are conceived of as orientations, various processes are considered to be highly interconnected and to operate interdependently, which allows for a rich and dynamic account of individuals' achievement goal strivings. Also, these Gestalt-like descriptions match well with many practitioners' observations of people's functioning in achievement settings.

However, this macro-approach of the definition of achievement goals may also have a number of disadvantages, which we discuss here (see also Senko, Hulleman, \& Harackiewicz, 2011). First, one potential pitfall is that achievement goal scholars do not take a clear stance on the core elements of the achievement goal construct. It remains unclear which elements (e.g., aims, reasons, feelings, attributions) represent the defining feature of the achievement goal construct and which elements are more peripheral.

Second, because these core elements are not clearly elucidated, the operationalization of this omnibus achievement goal becomes very difficult. In fact, a meta-analysis by Hulleman et al. (2010) pointed precisely to the variable operationalization of achievement goals, showing that depending on which aspects of this omnibus goal construct were assessed, the correlates of achievement goals were different. For instance, performance-approach goals were found to yield a positive relation with achievement in cases when their assessment was limited to the pursuit of normative standards as such (e.g., "My goal is to outperform others on a test"), whereas they yielded a negative relation with achievement in cases when egovalidation concerns were part of the operationalization (e.g., "My goal is to outperform others to prove my ability"). To put it bluntly, the current operationalizations of achievement goal 
orientations (as with many constructs in psychology) are a mess, as they fail to adequately map onto their intended facets (Hulleman et al., 2010).

Third, because different aspects of the omnibus goal construct are often operationalized simultaneously, it remains unclear which aspects are driving the observed effects (see also Brophy, 2005). For instance, a performance-approach goal item such as "I prefer to work on projects where I can prove my ability to others" (Vandewalle, 1997) contains multiple aspects, including a choice component ("I prefer"), a normative component (“others' achievements") and a self-validating component (“proving ability"). Similarly, a mastery-approach goal item like "An important reason why I do my class work is because I like to learn new things" (Midgley et al., 1998) yields both a reference to a particular goal ("learning new things") and a reason for doing so ("I like"). To gain more precise insight into which of these components are driving the observed (lack of) associations with outcomes, it is critical to identify the core element of the achievement goal construct and to separately assess the additional aspects so as to study their independent contribution in the prediction of outcomes. Therefore, rather than a macro-approach, a micro-approach is needed, in which the aims themselves are differentiated from the underlying reasons.

Fourth, because various aspects of the omnibus goal construct have been operationalized, incomplete or even inaccurate suggestions for practice may be formulated. For instance, the majority of achievement goal researchers have argued that mastery goals are conducive to learning, yet this message might be driven at least partly by the way such goals have been operationalized (Benita, Roth, \& Deci, in press). To illustrate, when a reason component (e.g., 'I like') is included in the operationalization of mastery-approach goals, its observed desirable correlates could be partially attributed to this additionally assessed reason rather than to the pursued aim itself. Yet, if other reasons (e.g., external pressures) would underlie learners' mastery-approach goal pursuit, its learning benefits may be less pronounced 
or even cancelled out (Benita, et al., in press). The consideration of these underlying reasons may thus lead to the formulation of a more nuanced set of recommendations for learners and educators.

For these reasons, we follow Elliot and collaborators' (Elliot \& Thrash, 2001) call to disentangle the omnibus goal construct. Given the competence-based nature of achievement goals, the core of the construct should be defined according to competence-based dimensions. As noted above, two dimensions have been highlighted as being particularly relevant, that is, (a) the way competence is defined (task-based, self-based, other-based) and (b) the way competence is valenced (i.e., as a negative outcome to be avoided or as a positive outcome to be approached; Figure 1). The identification of these two critical dimensions leads to a narrower definition of the achievement goal construct, thereby leaving out underlying reasons from the achievement goal construct.

Notably, because contemporary achievement goal researchers vary considerably in whether they perceive this conceptual change as positive or as an unfortunate deviation from the original conceptualization, the term Achievement Goal Approach was introduced (Elliot, 2005). So, rather than representing a unified theory, the achievement goal literature is currently characterized by a variety of related, yet in important ways different, perspectives. In our opinion, this diversity is not problematic as such. Yet, not all achievement goal researchers might be aware of these diverse perspectives and, as a result, they may fail to make an informed decision regarding whether they want to work from the macro- or from the micro-approach. The above list of the advantages and pitfalls associated with each approach may be helpful in making a deliberate choice in this respect. In our view, there is much to be gained by adopting the micro-approach, as the removal of the underlying reasons (e.g., "to show ability") from the conceptual and operational definition of achievement goals in favor of an exclusive focus on the aims (e.g., "do better than others") opens the door for a more 
systematic examination of the regulatory basis of achievement goals, which leads to Proposition One. This proposition in conjunction with four other propositions, which as a whole aim to advance current theorizing and research on achievement goal dynamics, are developed more fully in the second part.

\section{Part II: Towards a Systematic Examination of the "Why” of Achievement Goals}

\section{Proposition One: Articulation of the "Why" of Achievement Goals Provides an Account of its Diverse Regulatory Basis}

From a Single to a Diverse Set of Underlying Reasons. Although achievement goals indicate the direction of individuals' strivings in achievement situations, the adoption and pursuit of these goals needs to be regulated ongoingly. Herein, we maintain that this regulatory basis can differ substantially depending on the type of reason underlying individuals' goal pursuit. Stated differently, the regulatory basis of achievement goals manifests through the type of reasons that individuals hold for pursuing achievement goals. This critical feature of individuals' motivational functioning in achievement settings is referred to as the "why" of achievement goals in a non-technical way. The "why" of achievement goals is differentiated from the "what" of achievement goals, which represents the direction of individuals' functioning in achievement settings. More specifically, the direction is represented by the type of achievement aims that individuals hold and pursue, and the strength of endorsing these different goal-contents (see also Deci \& Ryan, 2000; Elliot \& Thrash, 2001; Sheldon, Ryan, Kasser, \& Deci, 2004). Figure 2 provides a graphical representation of these two critical features of individuals' achievement goal dynamics. To illustrate Figure 2, a student could focus on improving her exams scores from those of the past year (achievement aim) to prove that she is an intelligent person or to avoid the criticism of her parents (reasons). Similarly, a volleyball player could focus on outperforming his or her 
opponent (achievement aim) because of the bonuses that are contingent on the outcome of the game or simply because he or she perceives competition as a challenge (reasons).

The critical point is that when achievement goals are treated as omnibus constructs, thereby failing to distinguish between aims and reasons, the regulatory basis of achievement goals cannot be considered separately. A further consequence of the comingling of the "what" and the "why" of achievement goals is that the reasons underlying achievement goals are treated in a homogeneous way. That is, each of the achievement goals would by definition be guided by one single type of underlying reason. Specifically, other-based goals would by definition be pursued to validate one's ego and self-worth, while task-based goals would be freed of any ego-validation concerns. Yet, this does not need to be case. Once achievement goals are restricted to aims as such, it becomes clear that these aims can be guided by diverse reasons. For instance, one could be focused on outperforming peers on an entrance exam for medical school in order to validate one's ego, but also because one personally values becoming a medical doctor. Further, ego-concerns are not only the driving force behind the goal to outperform others, but are often also guiding people's attempts to keep up with their past performances or even to master the requirements of a task.

These examples illustrate that the removal of the "reason" from the core of the achievement goal construct does not imply its abandonment. On the contrary, this removal opens the door for a more systematic consideration of a diversity of reasons underlying each of the achievement aims. Such an approach also better fits with what is witnessed in everyday life, as many individuals pursuing the same achievement goals may have different reasons for doing so. In addition, different achievement goals could be motivated by the same underlying reason, a possibility that cannot be recognized when aims and reasons are intertwined.

Summary. The conceptual separation of the reasons underlying achievement goals from the achievement goals themselves creates the exciting possibility that the ongoing 
regulation of achievement goals can be studied in greater detail. This regulatory basis can now be conceived of in a more diverse way, as a variety of reasons can undergird individuals' achievement goal striving. Of course, the study of this regulatory process brings new challenges. The most pressing question at this moment is perhaps how these underlying reasons can be conceptualized, which leads us to Proposition Two.

\section{Proposition Two: Articulation of the "Why" of Achievement Goal Pursuit Opens the Possibility to Insert Self-Determination Theory (and Other Theories) in the}

\section{Achievement Goal Approach}

Autonomous and Controlled Regulation. Separating the reasons underlying achievement goals from aims per se opens the possibility to conceptualize reasons by making use of other prevailing theories in the motivation literature. One motivation theory that is well-suited for this purpose is SDT (Deci \& Ryan, 2000; Ryan \& Deci, 2000a), a wellvalidated theory on optimal motivation, wellness, and personality functioning. Beginning with the classic distinction between intrinsic and extrinsic motivation (Deci, 1975), the theory has been refined by distinguishing different types of extrinsic motivation, such that the differentiation between controlled or pressured and autonomous or more volitional forms of regulation is now well-accepted (Ryan \& Deci, 2000b; Vansteenkiste, Lens, \& Deci, 2006).

Controlled regulation has two subcomponents, that is, (a) external regulation, which refers to engaging in an activity to meet external expectations, to obtain promised rewards, or to avoid sanctions and (b) introjected regulation, which refers to engaging in an activity to avoid feelings of guilt or shame or to bolster one's ego (Assor, Vansteenkiste, \& Kaplan, 2009). Although both types of controlled regulation come with feelings of pressure, they differ with respect to their originating source: whereas the pressure is coming from the outside in the case of external regulation (as the term implies), people pressure themselves in the case of introjected regulation. This process of partial internalization can be derived etymologically 
from the term introjection which, in Latin, is composed of the words "in" or "inside" and "jacere" or "to throw" (Vansteenkiste, Niemiec, et al., 2010). Thus, the regulatory basis of the behavior has almost literally been thrown inside; yet, little psychological work has been carried out to further transform this internally pressing form of regulation into one that is more personally adhered to. Instead, when introjected, a person still functions in an internally conflicted and rigid way, as s/he feels pressured to attain certain outcomes.

Autonomous regulation involves acting in a more unified and volitional way and also includes different subcomponents. The prototypical example of autonomous functioning is intrinsic motivation, which refers to engagement in an activity because it is fun, interesting, exciting, or challenging. Even if interest in the activity at hand is absent, one can still engage in the behavior willingly, at least if one perceives the activity as personally meaningful (identified regulation) or when the activity is seen as being consistent with other personally held ideals and values (integrated regulation). In these cases, one will be committed to the activity because the reason for enacting the behavior has been accepted (i.e., internalized), such that regulation of the activity occurs more willingly. Autonomous and controlled regulation represent two qualitatively different modes of functioning, with controlled regulation more easily consuming limited energetic resources and autonomous regulation being conducive to feelings of vigor and energy, as one is basically doing what one really wants to do (Moller, Ryan, \& Deci, 2006).

There are literally hundreds of studies across various life domains, including work, sports, psychotherapy, education and health care that provide empirical support for the autonomy-control distinction. The vast majority of past and ongoing work has examined people's autonomous and controlled reasons for engaging in a particular behavior. These studies have convincingly shown that autonomous reasons for activity engagement relate to a host of desirable outcomes, including better learning and performance, greater use of self- 
regulation strategies, maintained persistence, engagement, and well-being, while controlled reasons fail to predict these outcomes or even relate to undesirable outcomes, including maladaptive coping, ill-being, and even psychopathology (Deci \& Ryan, 2000; see Vansteenkiste, Niemiec, et al., 2010 for an overview).

Although it has been argued that the different types of regulation can also be applied to the way people regulate the setting and pursuit of their goals (e.g., Sheldon \& Kasser, 1995; Soenens \& Vansteenkiste, 2011), few studies have addressed this possibility empirically. In a few studies conducted within the context of the self-concordance model (e.g., Sheldon \& Kasser, 1995; Sheldon \& Elliot, 1998), participants were instructed to self-generate their personal goals and were then asked to rate a number of standardized questions about why they were pursuing each of their goals. The reasons represented participants' autonomous (or selfconcordant) and controlled (or disconcordant) reasons as articulated within SDT. Overall, these studies showed that the more participants' personal goals were regulated autonomously rather than in controlled fashion, the higher the likelihood they attained their goals, which, in turn, related to higher well-being. Such findings have been replicated in a variety of domains, including work (e.g., Greguras \& Diefendorf, 2010), psychotherapy (e.g., Michalak, Klappheck, \& Kosfelder, 2004), identity development (Soenens, Berzonsky, et al., 2011), and sports (e.g., Smith, Ntoumanis, \& Duda, 2007).

Herein, we argue that the autonomous-controlled distinction is also useful in considering the regulatory basis of achievement goals, at least when achievement goals are defined purely in terms of standards and aims. As shown in Figure 3, each of the achievement goals in the $3 \times 2$ framework can be regulated by relatively more autonomous or controlled reasons. To illustrate, a learner could focus on avoiding doing worse than her peers (otheravoidance goal) because she would feel ashamed if she would fail (controlled reason) or because performing poorly compared to others in her class would seriously hamper her future 
career (autonomous reason). A marathon runner could be focused on improving her personal best running time (self-approach goal) because this would give a serious boost to her ego (controlled reason) or because she sees the race as an exciting challenge (autonomous reason). Finally, an employee could be focused on mastering a new software program (task-approach) because his boss expects him to do so as quickly as possible (controlled reason) or because he is really interested in the new software program (autonomous reason).

To operationalize the theoretical notion that achievement goals can be undergirded by autonomous or controlled reasons, Vansteenkiste et al. (2010) introduced a method of assessment that follows, to some degree, the format developed by Sheldon and colleagues in their self-concordance model. In this method of assessment, participants are given a set of achievement goal items that assess the strength of their endorsement of a particular achievement aim (e.g., "My aim is to outperform others"). These items need to be "pure," that is, uncontaminated with aspects such as reasons that are peripheral to the achievement goal construct. In a second step, participants were provided with items tapping into the reasons why they would adopt the particular achievement goal. These items reflected both autonomous and controlled reasons. This approach allows for the creation of separate scores for participants' strength of achievement goal pursuit and for the autonomous and controlled reasons for pursuing the achievement goal. Accordingly, this approach allows for a simultaneous investigation of the "what" of goal pursuit, which varies in content and strength or intensity, and the "why" of goal pursuit, which varies by type of reasons (autonomous or controlled).

Theoretical Considerations. Having discussed the theoretical possibility that achievement goals can be driven by different reasons and the operationalization of this possibility, we would like to make five additional points to clarify our position. First, although these diverse reasons might undergird different achievement goal strivings, it is 
certainly possible that some achievement goals tend to be regulated, on average, in a particular way. For instance, the reasons underlying avoidance goals might on average be relatively more controlled and less autonomous compared to the reasons underlying approach goals (e.g., Elliot \& Sheldon, 1998).

Second, some of the reasons discerned within SDT are reminiscent of, if not completely overlapping with, the reasons that are said to guide performance- and masterybased goal pursuits when one conceives of achievement goals as an omnibus construct. Specifically, the ego-involving character of performance goals (Nicholls, 1984) is similar to an introjected mode of functioning in SDT (Ryan, 1982; Niemiec, Ryan, \& Brown, 2008). Also, the inherent pleasure, curiosity, and challenge-seeking typical of intrinsic motivation have often been conceived of as the underlying reasons for a mastery-orientation within the omnibus goal viewpoint (Nicholls, 1984). So, what do we gain by taking out these reasons and subsequently putting them back in? The added value is that ego-concerns and intrinsic pleasure are now conceived as reasons that can be applied to each of the achievement aims rather than as reasons that are characteristic exclusively of one particular achievement aim.

Third, although achievement aims are inherently competence-based, this need not be the case for their underlying reasons. Some of these reasons yield a reference to competence (e.g., proving one's self-worth), whereas others do not (e.g., obtain a promised reward). Such non-competence based reasons deserve also attention. Indeed, the reasons underlying achievement goals were precisely removed from the concept of achievement goals because some of these reasons were not competence-based, while the type of achievement aims individuals pursue need to be grounded in competence (Elliot \& Thrash, 2001). For this reason, we also refrain from using the term achievement motive when speaking about the autonomous and controlled reasons underlying achievement goals, a term that is reserved for 
the concepts of need for achievement and fear of failure. Yet, we do use the term achievement goals, precisely because the aims themselves are, by definition, grounded in competence.

Fourth, the autonomous-controlled distinction within SDT just represents one way to conceptualize the reasons underlying achievement goals. Other scholars have used related, yet somewhat different operationalizations of the "why" of achievement goals (e.g., Ehrlich, 2012; Urdan \& Mestas, 2006).For instance, Dompnier et al. (2009) showed that the pursuit of mastery goals to garner teachers' attention (social desirability) or to succeed at the university (social utility) altered the relation between mastery goal pursuit and achievement. Clearly, these two sets of reasons shared conceptual overlap with some of the reasons within SDT. Specifically, social desirability reasons and external regulation both share a focus on pursuing an achievement goal to meet external criteria (controlled regulation), while a social utility reason reflects the more personal value of the achievement goal such that learners could come to identify with the goal (autonomous regulation).

Fifth, some readers may wonder how the study of the reasons underlying achievement goals goes beyond past empirical work that examined the relations between concepts from the achievement goal approach and SDT (e.g., Gao, Podlog, \& Harrison, 2012; Standage, Duda, \& Ntoumanis, 2003). Although informative at the empirical level, we maintain that for real integration to take place, more is needed than the identification of an empirical link between constructs. Without a compelling theoretical argument, one may be able to compile a broader model, yet such an empirically driven model does not necessarily reflect true theoretical integration. That is, there needs to be a conceptual basis and necessity to invoke the term integration and to move towards an integrated motivational model. The detachment of reasons from aims creates this necessity and provides the conceptual space for the SDT-framework to become integrated more deeply within modern theorizing on achievement goals. 
Summary. The achievement goal approach and SDT have become extremely popular over the past two decades as frameworks from which to study individuals' motivational dynamics in diverse achievement domains (e.g., education, sports, work). Yet, few studies have made use of both frameworks simultaneously, perhaps due to the lack of a compelling theoretical argument. The detachment of reasons from the concept of achievement goals opens the possibility to simultaneously study people's achievement goals as such and the controlled and autonomous reasons underlying these goals. Although this field is in its infancy, the few studies conducted to date adopting such an integrative approach already provide more nuanced insights into the motivational dynamics in achievement settings. This small body of work, at present, is reviewed in the next section.

\section{Proposition Three: Autonomous and Controlled Reasons Underlying Achievement}

\section{Goals Matter on Top of the Strength and Type of Achievement Goal Pursuit}

On the Functional Significance of Achievement Goals. On the basis of SDT we argue that autonomous and controlled regulations behind the pursuit of achievement goals will relate differentially to cognitive, affective, and behavioral outcomes and that they will predict variance in those outcomes in addition to the variance explained by the strength of the endorsement of achievement goals per se. This prediction is displayed graphically in the righthand part of Figure 4 . The reason why the underlying motivational regulations of achievement goals may matter above and beyond the achievement goals themselves is that they alter the functional significance or the attributed meaning of the goal (Deci \& Ryan, 1985). That is, when undergirded by controlled reasons, the achievement goal would be experienced in a more evaluative and pressured way, as individuals would have the impression that their (lack of) progress and attainment of a particular achievement goal would reflect on their self-worth. In contrast, when regulated by autonomous reasons, the informational value of the goal would be made more salient, as the goal would be seen as a way to provide guidance for one's 
functioning and as a "helpful tool" to promote growth. As a result of these differences in attributed meaning, the different types of goal regulation would relate in distinct ways to satisfaction of the basic psychological need for autonomy which, in SDT, is defined as the need to experience a sense of choice and psychological freedom (versus experiencing pressure). As a consequence of their differential associations with the need for autonomy, the two types of regulations of achievement goals would relate differentially to outcomes, with an autonomous regulation relating to relatively more adaptive behaviors, cognitions, and emotions than a controlled regulation (see Gillet, Lafrenière, Vallerand, Huart \& Fouquereau, 2014).

From the SDT-perspective, two other basic psychological needs have been formulated, that is, the need for competence (i.e., experiencing a sense of effectiveness) and the need for relatedness (i.e., experiencing a sense of interpersonal warmth). Although the two types of regulations of achievement goals may primarily relate differently to the need for autonomy, we argue that they may also relate differentially to these two other needs. That is, an autonomous goal regulation would be conducive to activity absorption, which would allow for better skill development and, hence, greater levels of competence satisfaction. Also, the controlled regulation of at least some achievement goals may yield a relational cost, as others would be more likely to be perceived as instrumental to meeting one's preferences or as obstacles to be removed so that one can achieve one's goals (see Gillet et al., 2014).

Empirical Basis. In total, 11 studies conducted by five different research teams have tested the hypothesis that the two types of regulation would relate differentially to outcomes and would explain incremental variance beyond the contribution of achievement goals per se. The key features of these studies are listed in Table 1.

Using the approach described in the preceding paragraph, Vansteenkiste, Smeets et al. (2010) focused exclusively on learners' performance-approach goals, as these goals are the 
ones that are most heavily debated in the achievement goal literature (Brophy, 2005;

Harackiewicz, Barron, \& Elliot, 1998; Harackiewicz, Barron, Pintrich, Elliot, \& Thrash, 2002;

Midgley, Kaplan, \& Middleton, 2001; Senko et al., 2011). They reasoned that the type of reasons why individuals adopt a performance-approach goal may relate to their pattern of outcomes above and beyond the strength of endorsing performance-approach goals. Across two cross-sectional studies, they obtained strong evidence for this claim, with reasons accounting for incremental variance in all 17 measured outcomes after having inserted performance-approach goal strength in a first step in a hierarchical regression analysis. Autonomous reasons (e.g., 'Because I find this a personally valuable goal') and controlled reasons (e.g., 'Because I have to comply with the demands of others such as parents, friends, and teachers') underlying performance-approach goals were found to matter for a diversity of critical aspects of the learning process.

First, whereas controlled regulation of performance-approach goals yielded a negative relation to individuals' global scholastic attitude, autonomous regulation of performanceapproach goals yielded a positive relation. Second, both types of regulation were related differentially to the way individuals engaged in the learning process and their level of absorption during the learning process. Specifically, autonomous regulation related to better planning and time management, a more absorbed approach to the learning activity, and a greater selection of main ideas while learning, while a controlled regulation generally yielded the opposite pattern. Moreover, when facing obstacles, autonomously regulated performanceapproach goals were predictive of greater persistence to overcoming problems, while pressure to outperform others related to giving up more easily. Third, presumably because of the poorer preparation for tests precipitated by the controlled regulation of performance-approach goals, and due to the experienced pressure to outperform others on the test, controlled regulation also related to more test anxiety and lower objective achievement. 
Two additional findings need highlighting. First, the observed associations between the reasons underlying performance-approach goals and outcomes remained largely significant after controlling for the strength of mastery-approach goals as well. This suggests that the contribution of the "why" of performance-approach goals is not reducible to or cannot be explained away by the endorsement of another achievement goal. Second, the initially observed associations between the strength of performance-approach goals per se and learning outcomes fell below significance after controlling for underlying reasons for the majority of outcomes, suggesting that, at least for the outcomes in that particular study, the reasons underlying performance-approach goals were comparatively more critical in predicting outcomes than the strength of performance-approach pursuit as such.

In a more recent study by Gillet et al. (2014), who made use of the same assessment procedure as Vansteenkiste et al. (2010), evidence was obtained for the unique predictive contribution of performance-approach goal pursuit over and above the underlying reasons for other outcomes, including effort-expenditure and goal-attainment. Specifically, individuals more strongly endorsing performance-approach goals were found to invest greater effort in their goal striving, leading them to better attain their goals over time. This effect emerged above and beyond the positive contribution of the autonomous reasons underlying performance-approach goals.

Consideration of the reasons underlying performance-approach goals is not only critical for individuals' goal-related effort-expenditure and learning outcomes, but for their moral functioning as well. Specifically, Vansteenkiste, Smeets et al. (2010) reported that controlled regulation of performance-approach goals related to a more tolerant attitude towards cheating and to more self-reported cheating, while the opposite pattern emerged for autonomous regulation of performance-approach goals. Thus, when feeling pressured to beat 
another person, individuals might go to great lengths to achieve their desired goal and do not seem to hesitate to rely on unethical strategies to fulfill their ambitions.

A similar pattern of findings was obtained in a subsequent study conducted with two samples of soccer players (Vansteenkiste, Mouratidis, \& Lens, 2010). An essential aspect of most sports involves competing with others. As such, the question can be raised as to whether competition puts people at risk for behaving unfairly or whether such behaviors would rather be predicted by the reasons underlying one's engagement in competitive contexts. Across both samples, controlled regulation (e.g., 'because I would feel bad, guilty, or anxious if I wouldn't pursue this goal') of performance-approach goals, but not the strength of performance-approach goals, was associated with more antisocial behavior on the soccer pitch. The reason that controlled regulation of performance-approach goals related to more aggressive play was that pressure related to a more objectifying attitude towards one's opponent (Bandura, 1999; Haslam, 2006). Specifically, when placed under pressure, one is more likely to reduce one's opponent on the field to an object or a barrier that needs to be removed, if necessary by all possible means. The adoption of such an attitude was found to lower the threshold for aggressing against players on the other team, thus serving as a rationalization for aggressive behavior. In addition to relating to these behavioral outcomes, the pursuit of performance-approach goals for autonomous reasons was found to relate to positive affect and vitality, while the controlled regulation of performance-approach goals related to negative affect (Gillet et al., 2014; Vansteenkiste, Mouratidis et al., 2010).

A third set of studies (Benita, et al., in press; Gaudreau, 2012; Michou et al., provisional acceptance) addressed reasons underlying achievement goals other than performance-approach goals. Specifically, Michou et al. (provisional acceptance) reported that the autonomous and controlled reasons underlying both mastery-approach and performance-avoidance goals in a sample of Greek learners related to self-regulated learning 
above and beyond the strength of endorsing the achievement goals per se. Whereas performance-approach goals were found to yield minimal unique relations with learning outcomes after controlling for their underlying reasons (Vansteenkiste, Smeets et al., 2010), mastery-approach goals uniquely predicted learning outcomes, suggesting that both the "what" and "why" component mattered with regard to mastery-approach goals. In a similar vein, Benita, et al. (in press) showed in a sample of $7-8^{\text {th }}$ grade Israeli students that both mastery-approach goal pursuit itself and the sense of choice accompanying this pursuit yielded a unique association with behavioral engagement and interest. Moreover, masteryapproach goals and sense of choice interacted synergistically in the prediction of both outcomes, such that the simultaneous presence of both yielded a supplementary positive effect on behavioral engagement and interest.

Evidence for the interaction between mastery-approach goals and underlying autonomous and controlled reasons was also reported by Gaudreau (2012). Different from Benita et al. (in press), however, a different type of interaction emerged. That is, no evidence for a main effect of mastery-approach goals was obtained, as the contribution of masteryapproach goals to learning outcomes was found to be qualified by the autonomous, relative to controlled, reasons underlying their pursuit. Specifically, mastery-approach goals related positively to academic satisfaction and performance when regulated by underlying autonomous reasons, while mastery-approach goals related positively to academic anxiety when regulated by underlying controlled reasons. Gaudreau (2012) reported similar evidence for the moderating role of autonomous, relative to controlled, reasons in the relation between performance-approach goals and learning outcomes. Specifically, whereas performanceapproach goals related positively to academic performance when regulated autonomously, they yielded a positive relation to academic anxiety and a negative relation to academic satisfaction when regulated in a controlling manner. 
Furthermore, a recent six-week longitudinal study by Vansteenkiste, Mouratidis, Van Riet, and Lens (2014) among volleyball players extended previous work in two ways. First, each time for a period of 6 consecutive games volleyball players rated their game-specific dominant achievement goals, their game-specific autonomous and controlled reasons, and a number of outcomes including game enjoyment, performance satisfaction, and prosocial and antisocial behavior. Rather than adopting the more classic between-person approach, this design allowed an examination of intra-individual (week-to-week) fluctuations in the goals, their underlying reasons, and outcomes (see also Gernigon, Arripe-Longuevill, Delignières, \& Ninot, 2004). Second, the assessment of players' achievement goals was restricted to their dominant goal (see Van Yperen, 2006). Specifically, participants were asked to rank-order their game-specific achievement goals (i.e., performance-approach, performance-avoidance, mastery-approach, mastery-avoidance). Subsequently, only the reasons for pursuing their dominant (i.e., most highly ranked) goal were assessed. The reason for shifting towards this dominant goal approach was that participants often have one achievement goal that is most salient to them. It is relatively less relevant to tap into reasons for pursuing a less valued goal, as these goals are less psychologically salient.

Extending previous work, within-person variability in the type of dominant achievement goals and the reasons underlying players' dominant achievement goal related to within-person variability in a host of outcomes. After controlling for the outcome of the game, it was found that in games during which players had adopted a mastery-approach goal as their dominant goal, they displayed more prosocial behavior toward their teammates, compared to games during which they had listed another achievement goal (i.e., mastery-avoidance, performanceapproach, or performance-avoidance) as their dominant goal. Game-to-game variation in dominant goal pursuit did not, however, relate to variation in anti-social behavior and game and performance satisfaction. As for the reasons underlying their mastery-approach goal 
pursuit, when volleyball players regulated their mastery-approach goal autonomously, they experienced the game as more enjoyable, were more satisfied with their performance, and reported engaging in more prosocial behavior. No unique contribution was found for a controlled regulation of mastery-approach goals.

This within-person study design lends considerable credence to the added value of considering people's underlying regulation of their achievement goals. This is because the regulatory basis of achievement goals can vary considerably, not only between people, but also within a single person as a function of the type of social environment one is exposed to. Thus, by considering the type of regulation underlying one's achievement goals, new opportunities are created to study people's achievement goals in a more dynamic fashion (see also Murayama et al., 2011).

The following four conclusions can be drawn from the research conducted thus far on reasons underlying achievement goals. First, the autonomous and controlled regulation of achievement goals matters in terms of predicting outcomes above and beyond the type and strength of endorsing achievement goals per se. Second, these underlying reasons have been found to matter for task-based, self-based, and other-based achievement goals. This is interesting because the study of the regulatory basis of achievement goals may at first seem primarily applicable to other-based goals. Yet, the data indicate that even task- and self-based goals can become regulated in a controlled manner. For instance, a child may feel pressure from his mother to master at least some of his assigned homework tasks. Third, the autonomous and controlled regulation of achievement goals matters in predicting diverse outcomes (e.g., type of learning, time management, moral functioning) and in diverse achievement domains (i.e., education, sports, work), underscoring the robustness of this distinction. Fourth, these different regulations not only vary between people, but also fluctuate within people over time, with resulting consequences for people's psychological functioning. 
Summary. Considered together, the existing studies indicate that both the "what" (i.e., type and intensity of achievement aims) and the "why" (i.e., the type of reasons) of achievement goals are important in accounting for achievement goal dynamics. Nevertheless, given the pattern of results at present, it seems reasonable to ask whether the effect of the "why" of achievement goals is so strong that the "what" may be ignored. We do not think so, for multiple reasons.

First, even after controlling for underlying reasons, the "what" of achievement goals has been found to yield an incremental contribution in predicting outcomes (e.g., Gillet et al., 2014), although it is possible that this conclusion might be goal dependent (as mastery-based goals seem to yield a more unique contribution than performance-based goals) and outcome dependent (with the "what" of goals mattering less for learning outcomes than goal attainment).

Second, in some studies the "what" and the "why" of achievement goals have been found to interact in predicting outcomes (e.g., Benita et al., in press; Gaudreau, 2012), suggesting that a particular reason by itself does not suffice, but rather that individuals also need to endorse achievement goals for particular underlying reasons to yield a (supplementary) effect.

Third, other studies have shown that reason A underlying achievement goal X predicts outcome $\mathrm{Z}$, while the same reason A underlying achievement goal Y does not predict outcome Z. For instance, while controlled reasons underlying performance-approach goals predicted more antisocial play (Vansteenkiste, Mouratidis, \& Lens, 2010), controlled reasons underlying mastery-approach goals did not predict antisocial play (Vansteenkiste, Mouratidis, et al., 2014). Also, while autonomous reasons underlying mastery-approach goals predicted academic satisfaction, the same reasons underlying performance-approach goals failed to predict similar satisfaction (Gaudreau, 2012). Thus, in some cases a specific combination of the "what" and the "why" of achievement goals, that is, a specific goal complex (Elliot \& 
Thrash, 2001) is most strongly predictive of a particular outcome. In short, more work in this area is needed before clarity is acquired regarding how and how much the "what" and "why" of achievement goals matter, and for which outcomes and under which circumstances.

\section{Proposition Four: Consideration of the Reasons Underlying Achievement Goals Allows}

\section{for the Study of a Richer Set of Contextual Forces Influencing Motivation}

The "What" and the "How" of Achievement Goal Promotion. Consideration of the reasons underlying achievement goals not only affords better prediction of outcomes, it also allows one to consider a broader and, hence, richer set of contextual forces that may influence people's motivation in achievement settings. The types of goals encouraged by the social environment, known as achievement goal structures (Ames, 1992), can be referred to as the "what" of achievement goal promotion. Different goal structures have been hypothesized and shown to predict different types of goals adopted and endorsed by individuals (Kaplan, Middleton, Urdan, \& Midgley, 2002). For instance, mastery goal structures relate to the adoption of mastery goals, while performance goal structures relate to the adoption of performance goals (e.g., Bong, Woo, \& Shin, 2013; Roeser, Midgley, \& Urdan, 1996). This finding is displayed graphically in Figure 4, where a path is drawn from the "what" of achievement goal promotion to the "what" of individual achievement goal pursuit.

Yet, the same achievement goal can be introduced and monitored very differently, thereby impacting on individuals' reasons underlying the pursuit of a particular achievement goal. An interesting feature of SDT is that it distinguished between different interpersonal styles that socialization figures (e.g., teachers, parents, and coaches) can rely on to foster different types of motivation. Specifically, it is maintained that an autonomy-supportive style fosters autonomous motivation and that a controlling style fosters controlled motivation (Grolnick, Deci, \& Ryan, 1997; Ryan \& Deci, 2000; Vansteenkiste et al., 2010). Autonomysupportive practices involve taking the frame of reference of the other person, the provision of 
desired choice, communication of the necessity and personal relevance of the introduced goals, and building in challenges (Reeve, 2009). A controlling approach involves pressuring others to act, think, or feel in particular ways, thereby essentially ignoring the other person's viewpoint and instead imposing one's own agenda. This could be achieved through the use of more externally pressuring strategies, such as the promise of rewards, the threat of sanctions, and the reliance on controlling language or internally controlling strategies (Soenens \& Vansteenkiste, 2010) such as conditional regard, guilt-induction, or shaming.

Consistent with this distinction, a wealth of studies have shown that more general autonomy-supportive and controlling interpersonal styles predict, respectively, individuals' autonomous and controlled motivational regulation (e.g., Grolnick et al., 1997; Soenens \& Vansteenkiste, 2010). Herein, we argue that the style of introducing and monitoring people's progress towards specific achievement goals will also relate to the way that achievement goals get regulated (i.e., autonomous or controlled). The path in Figure 4 from the "how" of achievement goal promotion, which can either be more autonomy-supportive or more controlling, to the "why" of personal achievement goals pursuit, which can either be more autonomous or more controlled, reflects this proposal. Overall then, a symmetrical model may be posited at the contextual and personal goal striving level. The "what" of goal promotion and the "what" of goal pursuit represent the strength of promoting and endorsing particular achievement goals, respectively. The "how" of goal promotion and the "why" of goal pursuit have a qualitative connotation, as they reflect the way that certain achievement goals are transmitted and the type of reasons why these goals are adopted and pursued.

A few examples might be helpful. A teacher could, for instance, emphasize to children that it is important for them to gradually make progress in their reading skills over the semester. Yet, she might convey this self-based goal in a number of different ways. Some teachers may rely on pressuring strategies, such as the use of contingent rewards or 
threatening sanctions to pressure the children to make sufficient progress. Other teachers may try to explain the value of such intra-individual progress and present the self-based goal in a more dialogical way, or they might provide choice to the children by allowing them to set their own intrapersonal goals, enabling children to fully endorse the goal and regulate it autonomously. Similarly, after a series of subsequent losses, a coach could emphasize the importance of not losing the upcoming competitive game during his pep talk, yet this otheravoidance goal could be communicated in various ways. Some coaches may put pressure on the players to avoid losing, saying for instance: "It is time to stand up and stop our losing streak." However, there is room for a coach to communicate this other-avoidance goal in a more autonomy-supportive way, saying for instance, that it might not be easy to avoid a loss, but that the players could view this as a challenge.

Theoretical Considerations. One question that may arise at this point is whether being autonomy-supportive inherently means that socializing agents leave it up to the individual to decide which goals to pursue. Stated otherwise, when socializing agents promote a particular achievement goal, are they by definition low on autonomy-support? In this respect, it is important to clarify that autonomy-support does not imply a permissive approach, characterized by unlimited freedom (Reeve, Jang, \& Deci, 2010; Vansteenkiste et al., 2012). Autonomy-supportive agents can regulate people's behavior by pointing toward a particular direction (e.g., an other-based goal), yet there is space for different ways of communicating this direction of behavior. For instance, a socializing agent could present an other-based goal as the only desirable goal to be pursued and leave no room for dialogue, in which case they would come across as controlling. Yet, the same achievement goal could also be explained with a meaningful rationale and the person's feelings regarding the goal could be validated, such that the person more fully endorses the goal and the proposed aspirations. Moreover, although individuals may not be given choice in the type of goal to pursue, thus being denied 
option-choice, they could be afforded action-choice, that is, choice regarding the level at which the goal is set and regarding how and when the goal could be achieved (Mouratidis, Vansteenkiste, Lens, \& Sideridis, 2011; Reeve, Nix, \& Ham, 2003).

The differentiation between the "what" and the "how" of achievement goal promotion also allows one to critically evaluate existing goal structure measures. As far as such measures mix elements of goal promotion per se with the way the goals are to be pursued, the resulting findings must be interpreted with caution, as they could be attributed to the promoted goals, the style of doing so, or both. Along similar lines, scripts used to experimentally induce particular achievement goals need to be reconsidered. For instance, in past work elements of challenge seeking and interest have often been implicitly intermingled with the experimental induction of mastery-approach goals per se (e.g., Bjornebekk, Gjesme, \& Ulriksen, 2011). In contrast, performance-approach goals sometimes have been introduced in a more controlling fashion, such that participants felt pressured to adopt a performance-approach goal (e.g., Crouzevialle \& Butera, 2013). Such ambiguous inductions do not allow one to draw clear conclusions, as multiple factors could explain the observed findings. Thus, we believe that a clear separation between the type of promoted achievement goals per se and the style used to introduce these achievement goals will provide more precise insight into the factors driving observed effects in past work.

Empirical Basis. There is some evidence for the importance of the way that achievement goals are promoted. First, Reeve and Deci (1996) showed that being pressured to outperform an opponent when working on an interesting puzzle solving task led to less subsequent intrinsic motivation compared to competing against an opponent under more informational circumstances. Second, similar findings were reported in a correlational study by Ciani, Middleton, Summers, and Sheldon (2010) who found that a performance-approach classroom structure was no longer negatively related to students' personal mastery-approach 
goal adoption when students experienced their teachers as autonomy-supportive. Third, Spray, Wang, Biddle, and Chatzisarantis (2006) experimentally induced either a mastery-approach or a performance-approach goal in golfers, crossing goal induction with an autonomy-supportive or more controlling style to communicate these goals. They reported a main effect of both goal-induction and communication style (but no interaction), with golfers being instructed in an autonomy-supportive, relative to controlling, way reporting greater enjoyment, persisting longer and performing better, and those placed in the mastery-approach, relative to the otherapproach, goal condition performing better; presumably, the way that golfers regulated their achievement goals was quite different, although the authors did not directly assess participants' reasons behind their goal pursuit. Finally, a recent study by Benita et al. (in press) found that experimental variation in the way that an intrapersonal goal was introduced affected participants' sense of choice and enjoyment. Specifically, an autonomy-supportive, relative to a controlling, introduction led to more positive emotional experiences. Together, these studies point to evidence for the claim that different styles of promoting the same achievement goals yields different outcomes, presumably because different styles activate different types of goal regulation.

Yet, many issues still need attention. For instance, most research to date has focused on the style of introducing or encouraging achievement goals, but no research has focused on the way that socializing agents monitor individuals' goal progress nor on the way that they provide feedback on goal attainment (or the lack thereof). Again, there is considerable variation in the way this can be done. For instance, a teacher could more closely monitor the progress of a child with reading difficulties out of a distrust that she is not reading spontaneously by herself, or because she is truly committed to seeing how the child is doing so as to provide help if needed (see Enzle \& Anderson, 1993). Also, the way that socializing agents respond to ultimate goal attainment could vary, with some displaying conditional 
positive feedback (e.g., "I'm glad you finally made some progress. That is what I was hoping for"; Ryan, 1982) and others providing unconditional positive feedback (e.g., "It is really nice you made some progress"). Although the socializing agent provides positive feedback in both instances, it is clear that the person feels pressured to keep up with her advanced level and is expected to make more progress when the positive feedback is conditional. Along similar lines, the style of providing corrective feedback after a lack of goal attainment could be either fairly harsh, demeaning, and controlling or more informational, considerate, and autonomysupportive (Mouratidis, Lens, \& Vansteenkiste, 2010).

A second issue that needs to be sorted out is whether a particular style of introducing and monitoring achievement goals strengthens or decreases their pursuit over the short- or longterm. Thus, if a teacher were to use pressure in introducing a particular achievement goal, students might temporarily become more strongly focused on the goal, yet they may give up the goal quickly if progress is not immediately evident. This is because the controlled regulation of achievement goals would require more energy (Ryan \& Fredericks, 1997). Along similar lines, it is possible that some promoted achievement goals not only relate to the strength of goal striving but also elicit a particular type of regulation. A teacher who is emphasizing the importance of not doing worse than others may not only prompt children to endorse other-avoidance goals, but may also provoke a controlled regulation. In other words, apart from the more self-evident symmetrical paths between contextual antecedents and personal goal pursuit (i.e., the "what" of goal promotion $\rightarrow$ the "what" of goal pursuit; the "how" of goal promotion $\rightarrow$ the "why" of goal pursuit), evidence could also be gathered for the cross-paths in Figure 4. Moreover, longitudinal research could examine whether the "what" and the "why" of achievement goal pursuit fuel back onto the environment, such that a mutually reinforcing virtuous or vicious cycle arises. For instance, when learners are capable 
of regulating their achievement goals out of curiosity and challenge, they may elicit more autonomy-supportive reactions from their socializing agents.

Summary. Much as research on personal goal pursuit has begun to move beyond consideration of the strength of pursuing particular achievement goals per se, we suggest that work at the contextual level would do well to move beyond the type of promoted achievement goals per se. This is because the way of introducing achievement goals may determine not only how strongly there are endorsed, but also the reasons why they are adopted. In our view, these are intriguing questions, as they suggest that in addition to competence dynamics (which are the central focus within the achievement goal literature), dynamics of autonomy also need to be taken into account to understand when and why people are thriving in achievement settings or failing to actualize their potential.

\section{Proposition Five: Consideration of the Reasons Underlying Achievement Goals Sets the}

\section{Stage for an Enriched Hierarchical Model of Achievement Motivation}

Personality Features as Antecedents. In addition to studying contextual antecedents of the "why" of achievement goal pursuit, recent research (Michou et al., provisional acceptance) has started to devote attention to personality features that may relate to the reasons underlying achievement goals. Michou et al. (provisional acceptance) argued that the antecedents identified within the hierarchical model would not only be predictive of the type of achievement goals individuals adopt ("what"), but also of the underlying reasons ("why") for their achievement goal pursuit. Thus, the incorporation of these underlying reasons would allow for an enrichment of the hierarchical model of achievement motivation.

Particular attention was paid to the motive to succeed and the motive to avoid failure, two competence-based motive dispositions (see Figure 4) that have been found to instigate the pursuit of achievement goals. The motive to succeed and the motive to avoid failure would not only get channeled through more specific achievement goals, but they would also 
concomitantly instigate a particular reasons underlying one's achievement goals. Interestingly then, although both the motive to succeed and the motive to avoid failure may manifest through the same achievement goal, they may provoke a different underlying reasons, that is, they may relate to a different regulatory basis. This is precisely what the data by Michou et al. (provisional acceptance) revealed. Whereas both the motive to succeed and the motive to avoid failure related to performance-approach goals, the motive to succeed and the motive to avoid failure predicted, respectively, an autonomous and controlled regulation of performance-approach goals. Taken together across two studies, across three types of assessed achievement goals (i.e., mastery-approach, performance-approach, and performanceavoidance), the motive to succeed and the motive to avoid failure were found to systematically relate to an autonomous and a controlled regulation of achievement goals, respectively. Presumably, the anxiety to fail leads individuals high in fear of failure to pay attention to the controlling and evaluative aspect of the achievement standards; achievement standards yield a more threatening character. In contrast, individuals high in the motive to succeed seem to focus more on the informational value of achievement standards, seeing them as a challenge and a springboard for growth rather than evaluation, which instigates a more autonomous regulation.

Moreover, the autonomous and controlled reasons underlying achievement goals played an important explanatory (i.e., intervening) role in the relation between these two competence-based motives and a host of different outcomes above and beyond the role of endorsing achievement goals per se (see Figure 4). That is, the need for achievement related to more adaptive learning outcomes such as critical thinking, effort regulation, and metacognitive regulation in part because it instigates a more autonomous regulation of achievement goals, whereas fear of failure yielded a negative association with effort regulation through the controlled regulation of achievement goals. 
Summary. Historically, the achievement goal approach has developed from the classic work on the need for achievement and fear of failure (Atkinson, 1964). We believe the current proposal for moving achievement goal theory forward needs to align with these historical roots. Consistent with this principle, recent research suggests that the motivational dispositions identified in the Atkinson tradition not only relate to the type of achievement goals that individuals pursue, but also to the reasons underlying their achievement goal pursuit. Of course, this research program is still in its infancy and many issues still remain to be sorted out. We sketch a few important directions for future research in the next section.

\section{Part III: Future Research Directions}

\section{Future Direction 1: To What Extent Can the Integrative Framework on the "What" and “Why” of Achievement Goals be Extended and Generalized?}

Broadening the Scope of Outcomes. Future research could examine the extent to which the effects of autonomous and controlled regulation of achievement goals can be linked to a broad variety of outcomes. Such work might be illuminating for many outcomes given that the relation between achievement goals themselves and outcomes has been found to be somewhat modest, suggesting there is room for other variables to account for incremental variance in the outcomes, such as the reasons underlying achievement goals. As also graphically displayed in Figure 4, these reasons have been linked to a diversity of affective (e.g., test anxiety, well-being), cognitive (e.g., surface- and deep-level learning) and behavioral (e.g., persistence, cheating, antisocial behavior) outcomes. Yet, future research could extend this set of outcomes, for instance, by including relational measures at the personal level (e.g., relational aggression, relationship quality) or group level (e.g., collaborative learning, group cohesion, group conflict). Based on SDT, one would predict the controlled regulation of achievement goals to go along with a more defensive mode of functioning (Hodgins \& Knee, 2002), because people's self-worth is then implicated in the 
goal-striving. Such ego-concerns may lead one to be more selective in sharing ideas, to be more critical vis-à-vis ideas deviating from one's own perspective, or even to destabilize another person's position in the group.

Broadening the Scope of Antecedents. In addition to competence-based motive dispositions (i.e., need for achievement, fear of failure), future research could examine a number of other antecedents of individuals' achievement goals and underlying reasons, such as the type of implicit theory of intelligence people hold (Dweck, 2012; Dweck \& Leggett, 1988). When people hold an entity theory, they believe their intelligence is set by nature. In contrast, when people hold an incremental theory of intelligence, they believe their intelligence is susceptible to change and can be developed. Several studies have found entity and incremental beliefs regarding intelligence to relate, respectively, to performance and mastery goals (e.g., Stipek \& Gralinski, 1996) and to differences in defensiveness in response to failure feedback (e.g., Nusbaum \& Dweck, 2008).

Importantly, in this research on implicit beliefs, achievement goals have been conceptualized and measured as global orientations. As a result, the "what" and "why" of achievement goals have not been disentangled. The move made herein to systematically distinguish between these features of achievement goal dynamics may shed new light on the relation between entity beliefs and achievement goals. That is, entity theorists may not only have a greater likelihood of adopting other-based achievement goals, they might also do so for controlled reasons. The belief that intelligence is fixed would lead entity theorists to feel pressured to show off their intelligence. In contrast, incremental theorists may not only be more likely to adopt task-based goals, they may also do so for autonomous reasons because they are curious and feel challenged to improve their skills and to cultivate their potential.

Generalization of Effects Across Groups, Domains, and Circumstances. Another question is the extent to which the relations for reasons underlying achievement goals hold up 
across different groups, different achievement domains, the prevailing achievement culture, and the broader cultural climate. The studies to date on reasons underlying achievement goals have been primarily conducted in the domains of education and sports, raising the question of whether similar findings would emerge in other achievement settings (e.g., work).

Further, the consideration of autonomous and controlled reasons may shed new light on the selective goal hypothesis (Barron \& Harackiewicz, 2001, 2003). This hypothesis involves the idea that the effects of achievement goals depend on the type of goals that are salient in one's social environment, with a match between one's personal achievement goals and the contextually promoted achievement goal yielding ideal outcomes. When this dynamic is applied to the regulation of achievement goals, it would seem that an autonomous regulation of achievement goals leads to positive outcomes in an autonomy-supportive environment, whereas a controlled regulation of achievement goals generates positive outcomes in a controlling environment. Although such findings may seem logical from a match-perspective (Higgins, 2005; Sagiv \& Schwartz, 2000), which is implied in the selective goal hypothesis, the prediction on the basis of SDT would be that the double portion of pressure coming from the controlled regulation of achievement goals as well as from the social environment yields a cost rather than a benefit (see also Murayama \& Elliot, 2009). Although the presence of these two forms of pressure may lead to short-term persistence and achievement as long as only superficial memorization is required, it may fail to lead to longterm persistence and deep-level learning (e.g., Grolnick \& Ryan, 1987; Vansteenkiste, Simons, Lens, et al., 2005). Also, it may produce considerable "collateral damage", including increased ill-being, poor social relationships (e.g., more relational aggression), and more unethical behavior (e.g., more cheating).

Similar reasoning applies at the cultural or national level. Because in some countries citizens face greater expectations and are placed under greater pressures for achievement (e.g., 
China; Chao, 1994), it might be relatively normative to regulate achievement goals on the basis of controlled reasons. This raises the question whether the costs associated with a controlled regulation of achievement strivings would get cancelled out in such societies (see Lansford et al., 2005 for an example in the parenting domain). According to the SDTperspective, this is unlikely because a pressuring environment and a pressuring form of regulation both fail to satisfy people's basic psychological need for autonomy, which is considered an essential nutrient for growth. To use a metaphor, the health costs of smoking are not cancelled if a teenager is growing up in a family where both parents are smoking, that is, a family where it is the norm to smoke. There exists some indirect evidence for this proposition, as a number of previous studies within the SDT-tradition has shown that individuals' autonomous, relative to their controlled, behavioral regulation (Chirkov, Ryan, et al., 2003; Jang, Reeve, Ryan, \& Kim, 2009), parental dependency (Chen, Vansteenkiste, Beyers, Soenens, \& Van Petegem, 2013), and personal goal pursuit (Sheldon et al., 2002) also yield well-being benefits for individuals growing up in collectivistic-oriented cultures. Such work has not been conducted yet with respect to the reasons underlying individuals' achievement goal pursuit, as all previous studies were conducted among individuals living in Western and rather individualistic-oriented cultures. The examination of the reasons underlying achievement goals in conjunction with the prevailing cultural ambiance in diverse cultures thus awaits further testing.

\section{Future Direction 2: Refreshing Insights on Goal-Attainment and Goal-Switching?}

Goal-Attainment. Another issue that could be addressed in future research is whether contextual and personality factors predict both the "what" and "why" of goal pursuit over time. For example, would it be the case that individuals high in fear of failure display an increase in controlled regulation over time and that the feelings of pressure and stress that go along with controlled regulation fuel concerns about failure over time, such that individuals 
high in fear of failure get stuck in a negative cycle? A more positive motivational dynamic is likely to characterize the functioning of individuals high in the need for achievement.

Further, research is needed on whether the valuation of achievement goals as well as the reasons underlying achievement goals uniquely relate to actual goal attainment. An additional possibility is that goal pursuit itself and the reasons underlying goal pursuit work in conjunction to produce goal attainment over time. For instance, individuals who strongly endorse outperforming others may achieve their normative ambitions, yet this association might be much more pronounced when their goals are regulated autonomously (see Gillet et al., 2014 for initial evidence in this regard).

In addition to examining whether the "what" and "why" of goal pursuit relate to goal attainment independently, the route through which such goal attainment is achieved needs to be examined. This is an interesting topic as goal attainment might be achieved via a dual route: that is, stronger goal-endorsement may - due to its outcome focus (Freund, Henneke, \& Mustafic, 2011; Freud, Henneke \& Riediger, 2010) - lead one to invest more time, energy, and resources in the goal at hand, leading to better goal attainment. Autonomous goal regulation may not only lead one to put additional effort in the goal pursuit (see Gillet et al., 2014), but also to approach the goal striving differently. That is, a process focus is more likely to occur under conditions of autonomous goal regulation (and intrinsic motivation in particular). Because the inherent satisfaction of pursuing the goal is central to intrinsically motivated goal pursuit, individuals are more likely to get fully immersed in the activity at hand. Thus, when regulating achievement goals autonomously, goal attainment may follow as a byproduct of goal striving. Controlled regulation of achievement goals, in contrast, may not involve such a process-focus and may instead make the outcome of goal attainment overly salient. In fact, when an outcome focus is paired with pressure to attain the goal, one may adopt an instrumental approach, both toward the activity at hand and toward others. That is, 
the learning activity would only be engaged in to attain the aspired goal, precluding full absorption in the activity and not allowing for full competence development. Similarly, others would be approached primarily with the aim of attaining the goal, leading one to use or even abuse others, causing damage to one's social relationships. Future research needs to examine whether such controlled regulation yields the same or different effects depending on whether normative, self-referenced, or task-based standards are used as a reference point.

Goal-switching. Apart from examining in greater detail the role of motivational factors and processes involved in goal-attainment, future longitudinal research could also examine whether the process of switching between different achievement goals can be predicted by their underlying regulation. Most recently, Corker, Donnellan, and Bowles (2013) examined the interdependence of college students' achievement goals across a four year time interval. Overall, they concluded that there was little evidence for systematic associations between different achievement goal trajectories and, more specifically, concluded, consistent with Senko et al. (2011), that no evidence was garnered for the often held argument (e.g., Brophy, 2005) that performance-approach goals may engender a vulnerability towards future avoidance goals.

The study of autonomous and controlled reasons underlying performance-approach goals may help shed light on the rank order stability of achievement goals and the switching between achievement goals. Specifically, when regulated autonomously, achievement goals might be more stable over time and give less room to goal switching, while controlled regulation may relate to lower rank order stability and a greater likelihood of goal switching. This is because when controlled, the regulatory basis is more fragile. Although people high in controlled regulation may initially stick to the adopted goal to prove their ego, when encountering enduring obstacles during goal-pursuit, they may more easily give up and switch to a different achievement goal. For instance, a learner who feels pressured by excessively 
high expectations of her parents to outperform peers on tests may more easily experience test anxiety (Vansteenkiste, Smeets et al., 2010), which would lower the threshold for turning toward avoidance-based goals. Feedback during goal pursuit may moderate this effect, with controlled regulations of achievement goals in particular eliciting goal switching when obstacles toward goal progress or attainment are encountered (see also Fryer \& Elliot, 2007). Importantly, such goal switching dynamics could not only occur from more adaptive to less adaptive achievement goals, but also the other way around. In addition, apart from looking at between-person goal switching, future work could examine in greater detail within-person goal switching, as the dominant type of achievement goal individuals held from one achievement situation to another may shift as a function of the reasons for pursuing the achievement goal.

\section{Future Direction 3: Towards a Different “Why”: Considering the Instrumentality of}

\section{Achievement Goals}

The work on autonomous and controlled reasons underlying achievement goals primarily taps into people's more dynamic reasons for pursuing achievement goals, that is, it reflects the extent to which people's achievement goals emanate from themselves and are infused with a sense of volition versus coercion. Yet, these reasons could also be defined more broadly, that is, as the long-term reasons or purposes that one aims to attain through pursuing current achievement goals. In that respect, instrumentality models (e.g., Eccles \& Wigfield, 2002; Husman \& Lens, 1999; Simons, Vansteenkiste, Lens, \& Lacante, 2004) could be used as a guiding framework to examine whether achievement goals are instrumental in reaching long-term goals, that is, in addressing the question whether there exists a helpful link between one's current achievement goals and future higher-level goals in the person's goalsystem. Such a question fits well with systemic viewpoints on goals (Carver \& Scheier, 1998) that address the "why" of achievement goals from a different angle. 
From the perspective of SDT, not all long-term goals are created equal, as a qualitative distinction is made between intrinsic goals, such as community contribution, selfdevelopment, and affiliation, and extrinsic goals, such as materialism, physical appeal, and popularity (Kasser \& Ryan, 1996). That is, the same achievement goal could stand in the service of attaining qualitatively different long-term goals. Imagine a music student focused on mastering a piece of music (i.e., task-approach goal) to gain social recognition and admiration (extrinsic goal) or to stretch her skills (intrinsic goal). Intrinsic and extrinsic life goals concern broader life aspirations that guide functioning beyond achievement settings, but that nevertheless can lead one to adopt certain achievement goals within a particular achievement setting or situation. A few studies have been conducted in this area. For instance, materialism and extrinsic goals have been found to relate to performance-approach goals and test anxiety (Ku, Dittmar, \& Banerjee, 2012), while intrinsic goals relate to mastery-approach goals and better performance (Mouratidis, Vansteenkiste, Michou, Lens, \& Soenens, 2013). While such research shows that life aspirations relate to the valuation of certain achievement goals, future research could address the corollary issue whether achievement goals that are instrumental for attaining different life aspirations yield different outcomes.

\section{Conclusion}

Over the past three decades, an extraordinary number of scholars have made use of the achievement goal framework. The contribution of this overview is to develop in a systematic way the theoretical and practical advantages associated with the detachment of reasons from achievement aims per se. We believe that this conceptual shift, already instigated by Elliot and colleagues more than a decade ago (Elliot \& Thrash, 2001), but elaborated more fully herein, opens exciting possibilities to advance the field. Specifically, it provides researchers with the opportunity to more thoroughly address the regulation of achievement goals and to bring different theoretical perspectives into the achievement goal literature. In particular, by 
Reasons underlying Achievement Goals

considering the autonomous and controlled reasons underlying achievement goals, the achievement goal literature could move from focusing primarily on competence-dynamics to paying greater attention to the dynamics of autonomy. The small yet rapidly growing empirical work on autonomous and controlled reasons underlying achievement goals reviewed herein yields promising results, but many unresolved issues remain. It is our hope that the continued study of these underlying reasons may help to expand the theoretical basis of the achievement goal literature, which may not only be beneficial to the achievement goal approach, but to motivational science more broadly. 


\section{References}

Ames, C. (1992). Classrooms: Goals, structures, and student motivation. Journal of Educational Psychology, 84, 261-271. doi: 10.1037//0022-0663.84.3.261

Ames, C. \& Archer, J. (1988). Achievement goals in the classroom: Students' learning strategies and motivation processes. Journal of Educational Psychology, 80, 260-267. doi: $10.1037 / / 0022-0663.80 .3 .260$

Assor, A., Vansteenkiste, M., \& Kaplan, A. (2009). Identified versus introjected approach and introjected avoidance motivations in school and in sports: The limited benefits of selfworth strivings. Journal of Educational Psychology, 101, 482-497. doi: $10.1037 / \mathrm{a} 0014236$

Atkinson, J. W. (1957). Motivational determinants of risk-taking behavior. Psychology Review, 64, 359-372. doi: 10.1037/h0043445

Atkinson, J. (1964). An introduction to motivation. New York: VNR. 6981870603

Atkinson, J. W., \& Feather, N. T. (1966). A theory of achievement motivation. New York: Wiley.

Bandura, A. (1999). Moral disengagement in the prepetration of inhumanities. Personality and Social Psychology Review, 3, 193-209.

Barron, K. E., \& Harackiewicz, J. M. (2001). Achievement goals and optimal motivation: Testing multiple goal models. Journal of Personality and Social Psychology, 80, 706722. doi: 10.1037//0022-3514.80.5.706.

Barron, K. E., \& Harackiewicz, J. M. (2003). Revisiting the benefits of performance-approach goals in the college classroom: Exploring the role of goals in advanced college students. International Journal of Educational Research, 39, 357-374. doi:10.1016/j.ijer.2004.06.004 
Benita, M., Roth, G., \& Deci, E. L. (in press). Are mastery goals adaptive? It depends on experiences of autonomy support and autonomy. Journal of Educational Psychology.

Bjornebekk, G., Gjesme, T., \& Ulriksen, R. (2011). Achievement motives and emotional processes in children during problem-solving: Two experimental studies of their relation to performance in different achievement goal conditions. Motivation and Emotion, 35, 351-367. doi: 10.1007/s11031-011-9224-y

Bong, M., Woo, Y., \& Shin, J. (2013). Do students distinguish between different types of performance goals? The Journal of Experimental Education, 81, 464-489.

Brophy, J. (2005). Goal theorists should move on from performance goals. Educational Psychologist, 40, 167-176. doi: 10.1207/s15326985ep4003_3

Carver, C. S., \& Scheier, M. F. (1998). On the self-regulation of behavior. New York: Cambridge University Press.

Chao, R. K. (1994). Beyond parental control and authoritarian parenting style: Understanding Chinese parenting through the cultural notion of training. Child Development, 65, 1111-1119. doi: 10.1111/j.1467-8624.1994.tb00806.x

Chen, B., Vansteenkiste, M., Beyers, W., Soenens, B., \& Van Petegem, S. (2013). Autonomy in family decision-making among Chinese adolescents: Disentangling the dual meaning of autonomy. Journal of Cross-cultural Psychology, 44, 1184-1209.

Chirkov, V., Ryan, R. M., Kim, Y., \& Kaplan, U. (2003). Differentiating autonomy from individualism and independence: A self-determination theory perspective on internalization of cultural orientations and well-being. Journal of Personality and Social Psychology, 84, 97-110.

Ciani, K. D., Middleton, M. J., Summers, J. J., \& Sheldon, K. M. (2010). Buffering against performance classroom goal structures: The importance of autonomy support and 
classroom community. Contemporary Educational Psychology, 35, 88-99. doi: 10.1016/j.cedpsych.2009.11.001

Corker, K. S., Donnellan, M. B., \& Bowles, R. P. (2013). The development of achievement goals throughout college: Modeling stability and change. Personality and Social Psychology Bulletin, 39, 1404-1417.

Deci, E. L. (1975). Intrinsic motivation. New York: Plenum.

Deci, E. L., \& Ryan, R. M. (1985). Intrinsic motivation and self-determination in human behavior. New York: Plenum.

Deci, E. L., \& Ryan, R. M. (2000). The "What" and "Why" of goal pursuits: Human needs and the self determination of behavior. Psychological Inquiry, 11, 227-268. Doi: 10.1207/S15327965PLI1104_01

Deci, E. L., \& Ryan, R. M. (2012). Motivation, personality, and development within embedded social contexts: An overview of self-determination theory. In R. M. Ryan (Ed.), Oxford handbook of human motivation (pp. 85-107). Oxford, UK: Oxford University Press.

Dompnier, B., Darnon, C., \& Butera, F. (2009). Faking the desire to learn: A clarification of the link between mastery goals and academic achievement. Psychological Science, 20, 939-943.

Dweck, C. S. (1986). Motivational processes affecting learning. American Psychologist, 41, 1040-1048. doi: 10.1037/0003-066X.41.10.1040

Dweck, C. S. (2012). Mindsets and human nature: Promoting change in the middle east, the schoolyard, the racial divide, and willpower. American Psychologist, 67, 614-622.

Dweck, C. S., \& Leggett, E. L. (1988). A social-cognitive approach to motivation and personality. Psychological Review, 95, 256-273. doi: 10.1037//0033-295X.95.2.256 
Eccles, J. S., \& Wigfield, A. (2002). Motivational beliefs, values, and goals. Annual Review of Psychology, 53, 109-132. doi: 10.1146/annurev.psych.53.100901.135153

Ehrlich, C. (2012). Be careful what you wish for but also why you wish for it - Goal-striving reasons and subjective well-being. The Journal of Positive Psychology, 7, 493-503.

Elliot, A. J. (1997). Integrating the 'classic' and 'contemporary' approaches to achievement motivation: A hierarchical model of approach and avoidance achievement motivation. In M. L. Maehr \& P. R. Pintrich (Eds.), Advances in motivation and achievement (Vol. 10, pp. 143-179). Greenwich, CT: JAI Press.

Elliot, A. J. (1999). Approach and avoidance motivation and achievement goals. Educational Psychologist, 34, 169-189. doi: 10.1207/s15326985ep3403_3

Elliot, A. J. (2005). A conceptual history of the achievement goal construct. In A. J. Elliot \& C. S. Dweck (Eds.), Handbook of competence and motivation (pp. 52-72). New York: Guilford.

Elliot, A. J., \& Church, M.A. (1997). A hierarchical model of approach and avoidance achievement motivation. Journal of Personality and Social Psychology, 72, 218-232. doi: $10.1037 / / 0022-3514.72 .1 .218$

Elliot, A. J., \& Harackiewicz, J. M. (1996). Approach and avoidance achievement goals and intrinsic motivation: A mediational analysis. Journal of Personality and Social Psychology, 70, 461-475. doi: 10.1037/0022-3514.70.3.461

Elliot, A. J., \& McGregor, J. A. (2001). A 2 X 2 Achievement goal framework. Journal of Personality and Social Psychology, 80, 501-519. doi: 10.1016/j.psychsport.2005.08.012

Elliot, A. J., McGregor, H. A., \& Gable, S. (1999). Achievement goals, study strategies, and exam performance: A mediational analysis. Journal of Educational Psychology, 91, 549-563. doi: 10.1037/0022-0663.91.3.549 
Elliot, A. J., \& Murayama, K. (2008). On the measurement of achievement goals: Critique, illustration, and application. Journal of Educational Psychology, 100, 613-628. doi: $10.1037 / 0022-0663.100 .3 .613$

Elliot, A. J., Murayama, K., \& Pekrun, R. (2011). A 3 X 2 achievement goal model. Journal of Educational Psychology, 103, 632-648. doi: 10.1037/a0023952

Elliot, A. \& Sheldon, K. (1998). Not all goals are personal: Comparing autonomous and controlled reasons for goals as predictors of effort and attainment. Personality and Social Psychology Bulletin, 24, 546-557. doi: 10.1177/0146167298245010

Elliot, A. J., \& Thrash, T. M. (2001). Achievement goals and the hierarchical model of achievement motivation. Educational Psychology Review, 13, 139-156. doi: 10.1023/A:1009057102306

Enzle, M. E., \& Anderson, S. C. (1993). Surveillant intentions and intrinsic motivation. Journal of Personality and Social Psychology, 64, 257-266. doi: 10.1037//0022-3514.64.2.257

Freund, A. M., Hennecke, M., \& Mustafić, M. (2012). On means and ends: Goal orientation and goal focus across adulthood. In R. Ryan (Ed.), Oxford Handbook of Motivation. Oxford: Oxford University Press.

Freund, A. M., Hennecke, M., \& Riediger, M. (2010). Age-related differences in outcome and process goal focus. European Journal of Developmental Psychology, 7,198-222.

Fryer, J., \& Elliot, A. J. (2007). Stability and change in achievement goals. Journal of Educational Psychology, 99, 700-714.

Gaudreau, P. (2012). Goal self-concordance moderates the relationship between achievement goals and indicators of academic adjustment. Learning and Individual Differences, 22, $827-832$. 
Gernigon, C., d' Arripe-Lngueville, F., Delignieres, D., \& Ninot, G. (2004). A dynamical systems perspective on goal involvement states in sport. Journal of Sport \& Exercise Psychology, 26, 572-596.

Gillet, N., Lafrenière, M-K. A. Vallerand, R. J., Huart, I., \& Fouquereau, E. (2014). The effects of autonomous and controlled regulation of performance-approach goals on well-being: A process model. British Journal of Social Psychology, 53, 154-174.

Greguras, G. J., \& Diefendorff, J. M. (2010). Why does proactive personality predict employee life satisfaction and work behaviors? A field investigation of the mediating role of the self-concordance model. Personnel Psychology, 63, 539-560.

Grolnick, W. S., Deci, E. L., \& Ryan, R. M. (1997). Internalization within the family: The self-determination theory perspective. In J. E. Grusec \& L. Kuczynski (Eds.), Parenting and children's internalization of values: A handbook of contemporary theory (pp. 135-161). New York: Wiley.

Harackiewicz, J. M., Barron, K. E., \& Elliot, A. J. (1998). Rethinking achievement goals: When are they adaptive for college students and why? Educational Psychologist, 33, 1-21. doi: 10.1207/s15326985ep3301_1

Harackiewicz, J. M., Barron, K. E., Pintrich, P. R., Elliot, A. J., \& Thrash, T. M. (2002). Revision of achievement goal theory: Necessary and illuminating. Journal of Educational Psychology, 94, 638-645. doi: 10.1037//0022-0663.94.3.638 Haslam, N. (2006). Dehumanization: An integrative review. Personality and Social Psychology Review, 10, 252-264. doi: 10.1207/s15327957pspr1003_4

Higgins, E. T. (2005). Value from regulatory fit. Current Directions in Psychological Science, 14, 209-213. 
Hodgins, H. S., \& Knee, C. R. (2002). The integrating self and conscious experience. In E. L. Deci \& R. M. Ryan (Eds.), Handbook of self-determination research (pp. 87-100). Rochester, NY: University Of Rochester Press.

Hofer, B. K., \& Pintrich, P. R. (1997). The development of epistemological theories: Beliefs about knowledge and knowing and their relation to learning. Review of Educational Research, 67, 88-140.

Hulleman, C. S., Schrager, S. M., Bodmann, S. M., \& Harackiewicz, J. M. (2010). A metaanalytic review of achievement goal measures: Different labels for the same constructs or different constructs with similar labels? Psychological Bulletin, 136, 422-449.

Hulleman, C. S., \& Senko, C. (2010). The future of achievement goal theory and research: The next 10 years. In T. Urdan, S. Karabenick, \& F. Pajares, Advances in motivation and achievement: Vol. 16. The decade ahead. London, England: Emerald.

Husman, J., \& Lens, W. (1999). The role of the future in student motivation. Educational Psychologist, 34, 113-125. doi: 10.1207/s15326985ep3402_4

Jang, H., Reeve, J., Ryan, R. M., \& Kim, A. (2009). Can self-determination theory explain what underlies the productive, satisfying learning experiences of collectivistically oriented Korean students? Journal of Educational Psychology, 101, 644-661. doi: $10.1037 / \mathrm{a} 0014241$

Kaplan, A., \& Maehr, M. L. (1999). Achievement goals and student well-being. Contemporary Educational Psychology, 24, 330-358. doi: 10.1006/ceps.1999.0993 Kaplan, A., Middleton, M. J., Urdan, T., \& Midgley, C. (2002). Achievement goals and goal structures. In C. Midgley (Ed.), Goals, goal structures and patterns of adaptive learning (pp. 21-53)._Mahwah, NJ: Lawrence Erlbaum. 
Kasser, T., \& Ryan, R. M. (1996). Further examining the American dream: Differential correlates of intrinsic and extrinsic goals. Personality and Social Psychology Bulletin, 22, 80-87. doi: 10.1177/0146167296223006

Knee, C. R., \& Zuckerman, M. (1996). Causality orientations and the disappearance of the self-serving bias. Journal of Research in Personality, 30, 76-87.

Ku, L., Dittmar, H., Banerjee, R. (2012). Are materialistic teenagers less motivated to learn? Cross-sectional and longitudinal evidence from UK and Hong Kong, Journal of Educational Psychology, 104, 74-86. doi:. 10.1037/a0025489

Lansford, J. E., Chang, L., Dodge, K. A., Malone, P. S., et al. (2005). Physical discipline and children's adjustment: Cultural normativeness as a moderator. Child Development, 76, 1234-1246. doi: 10.1111/j.1467-8624.2005.00847.x

Liem, A. D., Lau, S., \& Nie, Y. (2008). The role of self-efficacy, task value, and achievement goals in predicting learning strategies, task disengagement, peer relationship, and achievement outcome. Contemporary Educational Psychology, 33, 486-512. doi:10.1016/j.cedpsych.2007.08.001

Martin, A. J. (2006). Personal bests (PBs): A proposed multidimensional model and empirical analysis. British Journal of Educational Psychology, 76, 803-825. doi:

\section{$10.1348 / 000709905 \times 55389$}

Matos, L., Lens, W., \& Vansteenkiste, M. (2007). Achievement goals, learning strategies and language achievement among Peruvian high school students. Psychologica Belgica, 47, 51-70.

McClelland, D., Atkinson, J.W., Clark, R.A., \& Lowell, E.L. (1953). The achievement motive. N.Y.: Appleton-Century-Crofts, Inc.

Michalak, J., Klappheck, M. A., \& Kosfelder, J. (2004). Personal goals of psychotherapy patients: The intensity and the "why" of goal-motivated behavior and their 
implications for the therapeutic process. Psychotherapy Research, 14, 193-209. doi: $10.1093 / \mathrm{ptr} / \mathrm{kph} 017$

Michou, A., Mouratidis, A., Vansteenkiste, M., \& Lens, W. (provisional acceptance). Enriching the hierarchical model of achievement motivation: Autonomous and controlling reasons underlying achievement goals. British Journal of Educational Psychology.

Midgley, C., Kaplan, A., \& Middleton, M. (2001). Performance-approach goals: Good for what, for whom, under what circumstances, and at what cost? Journal of Educational Psychology, 93, 77-86. doi: 10.1037//0022-0663.93.1.77

Midgley, C., Kaplan, A., \& Middleton, M., Maehr, M. L., Urdan, T., Anderman, L., et al., (1998). The development and validation of scales assessing students' achievement goal orientations. Contemporary Educational Psychology, 23, 113-131. doi:

\subsection{6/ceps.1998.0965}

Moller, A. C., Deci, E. L., \& Ryan, R. M. (1996). Choice and ego-depletion: The moderating role of autonomy. Personality and Social Psychology Bulletin,, 32, 1024-1036. doi: $10.1177 / 0146167206288008$

Mouratidis, A., Lens, W., \& Vansteenkiste (2010). How you provide corrective feedback makes a difference: The motivating role of communicating in an autonomy-supporting way. Journal of Sport \& Exercise Psychology, 32, 619-637.

Mouratidis, A., Vansteenkiste, M., Lens, W., Michou, A., \& Soenens, B. (2013). Withinperson configurations and temporal relations of personal and perceived parentpromoted aspirations to school correlates among adolescents. Journal of Educational Psychology, 105, 895-910.

Muis, K. R. (2007). The role of epistemic beliefs in self-regulated learning. Educational Psychologist, 42, 173-190. 
Murayama, K., Elliot, A. J., \& Friedman, R. (2012). Achievement goals and approachavoidance motivation. In R. M. Ryan (ed.), The Oxford handbook of human motivation (pp. 191-207). Oxford: Oxford University Press.

Nicholls, J. G. (1984). Achievement motivation: Conceptions of ability, subjective experience, task choice, and performance. Psychological Review, 91, 328-346. doi: 10.1037/0033-295X.91.3.32

Niemiec, C. P., Ryan, R. M., \& Brown, K. W. (2008). The role of awareness and autonomy in quieting the ego: A self-determination theory perspective. In Wayment, H. A. and Bauer, J. J. (Eds), Transcending self-interest: Psychological explorations of the quiet ego.Decade of behavior (pp. 107-115). Washington, DC, US: American Psychological Association, xx, 263 pp.

Pintrich, P.R. (2000). An achievement goal theory perspective on issues in motivation terminology, theory, and research. Contemporary Educational Psychology, 25, 92104. doi: $10.1006 /$ ceps. 1999.1017

Reeve, J. (2009). Why teachers adopt a controlling motivating style toward students and how they can become more autonomy supportive. Educational Psychologist, 44, 159.175. $10.1080 / 00461520903028990$

Reeve, J., \& Deci, E. L. (1996). Elements of the competitive situation that affect intrinsic motivation. Personality and Social Psychology Bulletin, 22, 24-33.

Reeve, J., Jang, H., \& Deci, E. L. (2010). Engaging students in learning activities: It is notautonomy support or structure but autonomy support and structure. Journal ofEducational Psychology, 102, 588-600. doi: 10.1037/a0019682

Reeve, J., Nix, G., \& Hamm D. (2003). Testing models of the experience of selfdetermination in intrinsic motivation and the conundrum of choice. Journal of Educational Psychology, 95, 375-392. doi: 10.1037/0022-0663.95.2.375 
Roeser, R. W., Midgley, C., \& Urdan, T. C. (1996). Perceptions of the school psychological environment and early adolescents' psychological and behavioral functioning in school: The mediating role of goals and belonging. Journal of Educational Psychology, 88, 408-422. doi: 10.1037/0022-0663.88.3.408

Ryan, R. M. (1982). Control and information in the intrapersonal sphere: An extension of cognitive evaluation theory. Journal of Personality and Social Psychology, 43, 450461. doi: 10.1037//0022-3514.43.3.450

Ryan, R. M., \& Deci, E. L. (2000a). Self-determination theory and the facilitation of intrinsic motivation, social development, and well-being. American Psychologist, 55, 68-78. doi: 10.1037//0003-066X.55.1.68

Ryan, R. M., \& Deci, E. L. (2000b). Intrinsic and extrinsic motivations: Classic definitions and new directions. Contemporary Educational Psychology, 25, 54-67. doi: 10.1006/ceps.1999.1020

Ryan, R. M., \& Frederick, C. (1997). On energy, personality, and health: Subjective vitality as a dynamic reflection of well-being. Journal of Personality, 65, 529-565. doi: 10.1111/j.1467-6494.1997.tb00326.x

Sagiv, L., \& Schwartz, S. H. (2000). Value priorities and subjective well-being: Direct relations and congruity effects. European Journal of Social Psychology, 30, 177-198. doi: 10.1002/(SICI)1099-0992(200003/04)30:2<177::AID-EJSP982>3.0.CO;2-Z

Senko, C., \& Hulleman, C. S., \& Harackiewicz, J. M. (2011). Achievement goal theory at the crossroads: Old controversies, current challenges, and new directions. Educational Psychologist, 46, 26-47. doi: 10.1080/00461520.2011.538646

Sheldon, K. M., \& Elliot, A. J. (1999). Goal striving, need satisfaction, and longitudinal wellbeing: The self-concordance model. Journal of Personality and Social Psychology, 76, 482-497. doi: 10.1037//0022-3514.76.3.482 
Sheldon, K. M., Elliot, A. J., Ryan, R. M., Chirkov, V., Kim, Y., Wu, C., Demir, M., \& Sun, S.G. (2004). Self-concordance and subjective well-being in four cultures. Journal of Cross-cultural Psychology, 35, 209-223.

Sheldon, K. M., \& Houser-Marko, L. (2001). Self-concordance, goal attainment, and the pursuit of happiness: Can there be an upward spiral? Journal of Personality and Social Psychology, 80, 152-165. doi: 10.1037//0022-3514.80.1.152

Sheldon, K. M., \& Kasser, T. (1995). Coherence and congruence: 2 aspects of personality integration. Journal of Personality and Social Psychology, 68, 531-543. doi: $10.1037 / / 0022-3514.68 .3 .531$

Sheldon, K. M., \& Kasser, T. (1998). Pursuing personal goals: Skills enable progress but not all progress is beneficial. Personality and Social Psychology Bulletin, 24, 1319-1331.

Sheldon, K. M., Ryan, R. M., Deci, E. L., \& Kasser, T. (2004). The independent effects of goal contents and motives on well-being: It's both what you pursue and why you pursue it. Personality and Social Psychology Bulletin, 30, 475-486. doi: 10.1177/0146167203261883.

Simons, J., Vansteenkiste, M., Lens, W., \& Lacante, M. (2004). Placing motivation and future time perspective theory in a temporal perspective. Educational Psychology Review, 16, 121-139. doi: 10.1023/B:EDPR.0000026609.94841.2f

Skaalvik, E. (1997). Self-enhancing and self-defeating ego orientation: Relations with task and avoidance orientation, achievement, self-perceptions, and anxiety. Journal of Educational Psychology, 89, 71-81. doi: 10.1037/0022-0663.89.1.71

Smith, A., Ntoumanis, N., \& Duda, J. \& Vansteenkiste, M. (2011). Goal striving, coping, and well-being: A prospective investigation of the self-concordance model in sport. Journal of Sport \& Exercise Psychology, 33, 124-145. 
Spray, C. M., Wang, C. K. J., Biddle, S. J. H., \& Chatzisarantis, N. L. D. (2006).

Understanding motivation in sport: An experimental test of achievement goal and selfdetermination theories. European Journal of Sport Sciences, 6, 43-51. doi:

$10.1080 / 17461390500422879$

Soenens, B., \& Vansteenkiste, M. (2010). A theoretical upgrade of the concept of parental psychological control: Proposing new insights on the basis of self-determination theory. Developmental Review, 30, 74-99. doi:10.1016/j.dr.2009.11.001

Soenens, B., \& Vansteenkiste, M. (2011). When is identity congruent with the self? A selfdetermination theory perspective. In S. J. Schwartz, K. Luyckx, \& V. L. Vignoles (Eds.), Handbook of identity theory and research (pp. 381-402). New York: Springer.

Stipek, D. \& Gralinski, J. H. (1996). Children's beliefs about intelligence and school performance. Journal of Educational Psychology, 88, 397-407.

Tanaka, A., \& Yamauchi (2001). A model for achievement motives, goal orientations, intrinsic interest, and academic achievement. Psychological Reports, 88, 123-135. doi: 10.2466/PR0.88.1.123-135

Urdan, T., \& Mestas, M. (2006). The goals behind performance goals. Journal of Educational Psychology, 98, 354-365. doi: 10.1037/0022-0663.98.2.354

Vandewalle, D. (1997). Development and validation of a work domain goal orientation instrument. Educational and Psychological Measurement, 57, 995-1015. doi: $10.1177 / 0013164497057006009$

Van Yperen, N. W. (2006). A novel approach to assessing achievement goals in the context of the 2 X 2 framework: Identifying distinct profiles of individuals with different dominant achievement goals. Personality and Social Psychology Bulletin, 32, 14321445. 
Van Yperen, N.W., Blaga, M., \& Postmes, T. (in press). A meta-analysis of the impact of situationally induced achievement goals on task performance. Human Performance.

Vansteenkiste, M., Lens, W., \& Deci, E. L. (2006). Intrinsic versus extrinsic goal-contents in Self-Determination Theory: Another look at the quality of academic motivation. Educational Psychologist, 41, 19-31. doi: 10.1207/s15326985ep4101_4

Vansteenkiste, M., Mouratidis, A., \& Lens, W. (2010). Detaching reasons from aims: Fair play and well-being in soccer as a function of pursuing performance-approach goals for autonomous or controlling reason. Journal of Sport \& Exercise Psychology, 32, 217-242.

Vansteenkiste, M., Mouratidis, A., Van Riet, T., \& Lens, W. (2014). Examining correlates of game-to-game variation in volleyball players' achievement goal pursuit and underlying autonomous and controlling reasons. Journal of Sport \& Exercise Psychology, 36, 131-145..

Vansteenkiste, M., Niemiec, C., \& Soenens, B. (2010). The development of the five minitheories of self-determination theory: An historical overview, emerging trends, and future directions. In T. Urdan \& S. Karabenick (Eds.). Advances in Motivation and Achievement, vol. 16: The decade ahead (pp. 105-166). UK: Emerald Publishing. Vansteenkiste, M., Simons, J., Lens, W., Soenens, B., \& Matos, L. (2005). Examining the motivational impact of intrinsic versus extrinsic goal framing and autonomysupportive versus internally controlling communication style on early adolescents' academic achievement. Child Development, 76, 483-501. doi: 10.1111/j.14678624.2005.00858.

Vansteenkiste, M., Sierens, E., Soenens, B., Goossens, L., Dochy, F., Aelterman, N., Haerens, L., Mouratidis, A., \& Beyers, W. (2012). Identifying configurations of perceived 
Reasons underlying Achievement Goals

teacher autonomy support and structure: Associations with self-regulated learning, motivation and problem behavior. Learning and Instruction, 22, 431-439.

Vansteenkiste, M., Smeets, S., Lens, W., Soenens, B., Matos, L., \& Deci, E. L. (2010). Autonomous and controlled regulation of performance-approach goals: Their relations to perfectionism and educational outcomes. Motivation and Emotion, 34, 333-353. doi: 10.1007/s11031-010-9188-3.

Zusho, A., Pintrich, P., R., \& Cortina, K. S. (2005). Motives, goals, and adaptive patterns of performance in Asian American and Anglo American students. Learning and Individual Differences, 15, 141-158. doi:10.1016/j.lindif.2004.11.003 
Table 1

Schematic Overview of Studies Examining the "What" and "Why" of Personally Endorsed and the "What" and "How" of Contextually Promoted Achievement Goals

\begin{tabular}{|c|c|c|c|c|c|c|}
\hline Reference & $\begin{array}{l}\text { Personal goal pursuit / } \\
\text { Contextual goal } \\
\text { promotion }\end{array}$ & $\begin{array}{l}\text { Type of achievement } \\
\text { aim }\end{array}$ & Participants & Design & Domain & Outcomes \\
\hline \multicolumn{7}{|c|}{$\begin{array}{l}\text { Vansteenkiste, Smeets et al. } \\
(2010)\end{array}$} \\
\hline Study 1 & Personal goal pursuit & $\begin{array}{l}\text { Performance-approach } \\
\text { goals }\end{array}$ & $\begin{array}{l}\text { High school } \\
\text { students }\end{array}$ & $\begin{array}{l}\text { Cross- } \\
\text { sectional }\end{array}$ & Education & Cognitive, behavioral \\
\hline Study 2 & Personal goal pursuit & $\begin{array}{l}\text { Performance-approach } \\
\text { goals }\end{array}$ & $\begin{array}{l}\text { High school } \\
\text { students }\end{array}$ & $\begin{array}{l}\text { Cross- } \\
\text { sectional }\end{array}$ & Education & $\begin{array}{l}\text { Cognitive, behavioral } \\
\& \text { moral }\end{array}$ \\
\hline \multicolumn{7}{|c|}{$\begin{array}{l}\text { Vansteenkiste, Mouratidis, \& } \\
\text { Lens (2010) }\end{array}$} \\
\hline Study 1 & Personal goal pursuit & $\begin{array}{l}\text { Performance-approach } \\
\text { goals }\end{array}$ & Soccer players & $\begin{array}{l}\text { Cross- } \\
\text { sectional }\end{array}$ & Sport & Affective, moral \\
\hline Study 2 & Personal goal pursuit & $\begin{array}{l}\text { Performance-approach } \\
\text { goals }\end{array}$ & Soccer players & $\begin{array}{l}\text { Cross- } \\
\text { sectional }\end{array}$ & Sport & Moral \\
\hline \multicolumn{7}{|c|}{ Gillet, Lafrenière et al. (2014) } \\
\hline Study 1 & Personal goal pursuit & $\begin{array}{l}\text { Performance-approach } \\
\text { goals }\end{array}$ & $\begin{array}{l}\text { Undergraduate } \\
\text { students }\end{array}$ & $\begin{array}{l}\text { Cross- } \\
\text { sectional }\end{array}$ & Education & Affective, behavioral \\
\hline Study 2 & Personal goal pursuit & $\begin{array}{l}\text { Performance-approach } \\
\text { goals }\end{array}$ & Police officers & Longitudinal & Work & Affective, behavioral \\
\hline Gaudreau (2012) & Personal goal pursuit & $\begin{array}{l}\text { Performance-approach } \\
\text { and } \\
\text { mastery-approach goals }\end{array}$ & $\begin{array}{l}\text { Undergraduate } \\
\text { students }\end{array}$ & $\begin{array}{l}\text { Cross- } \\
\text { sectional }\end{array}$ & Education & Affective, cognitive \\
\hline \multicolumn{7}{|c|}{ Benita, Roth, \& Deci (in press) } \\
\hline Study 1 & Contextual goal induction & Mastery-approach goals & $\begin{array}{l}\text { College } \\
\text { students }\end{array}$ & Experimental & Education & Affective \\
\hline Study 2 & Personal goal pursuit & Mastery-approach goals & $\begin{array}{l}\text { High school } \\
\text { students }\end{array}$ & $\begin{array}{l}\text { Cross- } \\
\text { sectional }\end{array}$ & Education & Affective, behavioral \\
\hline
\end{tabular}


Table 1 (continued)

\begin{tabular}{|c|c|c|c|c|c|c|}
\hline Reference & $\begin{array}{l}\text { Personal goal pursuit / } \\
\text { Contextual goal } \\
\text { promotion }\end{array}$ & $\begin{array}{l}\text { Type of achievement } \\
\text { goal }\end{array}$ & Participants & Design & Domain & Outcomes \\
\hline $\begin{array}{l}\text { Vansteenkiste, Mouratidis, Van } \\
\text { Riet, \& Lens (2014) }\end{array}$ & Personal goal pursuit & Mastery-approach goals & $\begin{array}{l}\text { Volleybal } \\
\text { players }\end{array}$ & Longitudinal & Sport & Moral, affective \\
\hline \multicolumn{7}{|l|}{$\begin{array}{l}\text { Michou, Mouratidis et al. } \\
\text { (provisional acceptance) }\end{array}$} \\
\hline Study 1 & Personal goal pursuit & $\begin{array}{l}\text { Mastery-approach, } \\
\text { performance-approach } \\
\& \text { performance- } \\
\text { avoidance goals }\end{array}$ & $\begin{array}{l}\text { High school } \\
\text { students }\end{array}$ & $\begin{array}{l}\text { Cross- } \\
\text { sectional }\end{array}$ & Education & Cognitive \\
\hline Study 2 & Personal goal pursuit & Mastery-approach goals & $\begin{array}{l}\text { Undergraduate } \\
\text { students }\end{array}$ & $\begin{array}{l}\text { Cross- } \\
\text { sectional }\end{array}$ & Education & Cognitive \\
\hline $\begin{array}{l}\text { Spray, Wang, Biddle, \& } \\
\text { Chatzisarantis (2006) }\end{array}$ & Contextual goal induction & $\begin{array}{l}\text { Mastery-approach and } \\
\text { performance-approach } \\
\text { goals }\end{array}$ & Golfers & Experimental & Sport & Cognitive, behavioral \\
\hline
\end{tabular}


Figure 1

Graphical Representation of the 3×2 Model of Achievement Goals (Adapted from Elliot et al., 2011)

\begin{tabular}{|c|c|c|c|c|}
\hline & & DEFI & N OF CON & ENCE \\
\hline & & Task-based & Self-based & Other-based \\
\hline \multirow{2}{*}{ VALENCE } & \multicolumn{4}{|l|}{ Approach oriented } \\
\hline & \multicolumn{4}{|l|}{ Avoidance oriented } \\
\hline
\end{tabular}


Figure 2

Graphical Overview of Critical Features of Achievement Goal Dynamics

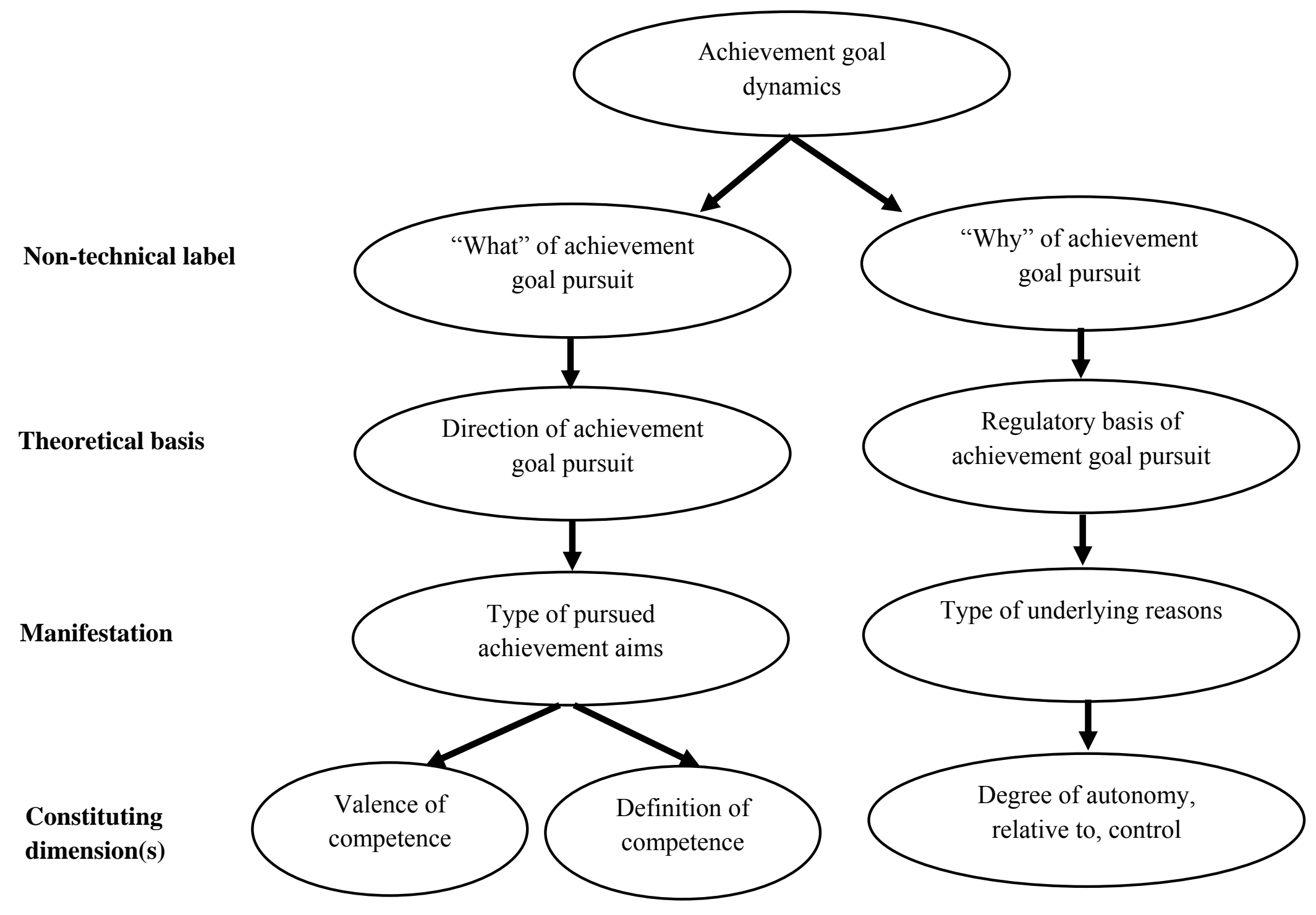


Figure 3

Graphical Representation of the Type of Reasons Underlying Different Types of Achievement Goals

\begin{tabular}{|c|c|c|c|c|}
\hline \multirow{9}{*}{ VALENCE } & \multirow{6}{*}{$\begin{array}{l}\text { Approach } \\
\text { oriented }\end{array}$} & & DEFINITION OF COMPETENCE & \\
\hline & & Task-based & Self-based & Other-based \\
\hline & & $\underline{\text { Autonomous Reasons }}$ & $\underline{\text { Autonomous Reasons }}$ & $\underline{\text { Autonomous Reasons }}$ \\
\hline & & $\begin{array}{l}\text { Attempting to master the requirements of } \\
\text { the task out of challenge, excitement, or } \\
\text { personal significance }\end{array}$ & $\begin{array}{l}\text { Attempting to do better than before } \\
\text { out of challenge, excitement, or } \\
\text { personal significance }\end{array}$ & $\begin{array}{l}\text { Attempting to do better than others } \\
\text { out of challenge, excitement, or } \\
\text { personal significance }\end{array}$ \\
\hline & & Controlled Reasons & $\underline{\text { Controlled Reasons }}$ & $\underline{\text { Controlled Reasons }}$ \\
\hline & & $\begin{array}{l}\text { Attempting to master the requirements of } \\
\text { the task out of internal pressure (e.g., } \\
\text { guilt, ego-concerns) or external pressure } \\
\text { (e.g., demanding expectations) }\end{array}$ & $\begin{array}{l}\text { Attempting to do better than before } \\
\text { out of internal pressure (e.g., guilt, } \\
\text { ego-concerns) or external pressure } \\
\text { (e.g., demanding expectations) }\end{array}$ & $\begin{array}{l}\text { Attempting to do better than others } \\
\text { out of internal pressure (e.g., guilt, } \\
\text { ego-concerns) or external pressure } \\
\text { (e.g., demanding expectations) }\end{array}$ \\
\hline & \multirow{3}{*}{$\begin{array}{l}\text { Avoidance } \\
\text { oriented }\end{array}$} & Autonomous Reasons & $\underline{\text { Autonomous Reasons }}$ & Autonomous Reasons \\
\hline & & $\begin{array}{l}\text { Attempting to avoid not mastering the } \\
\text { requirements of the task out of challenge, } \\
\text { excitement, or personal significance } \\
\text { Controlled Reasons }\end{array}$ & $\begin{array}{l}\text { Attempting to avoid doing worse than } \\
\text { before out of challenge, excitement, or } \\
\text { personal significance } \\
\text { Controlled Reasons }\end{array}$ & $\begin{array}{l}\text { Attempting to avoid doing worse } \\
\text { than others out of challenge, } \\
\text { excitement, or personal significance } \\
\text { Controlled Reasons }\end{array}$ \\
\hline & & $\begin{array}{l}\text { Attempting to avoid not mastering the } \\
\text { requirements of the task out of internal } \\
\text { pressure (e.g., guilt, ego-concerns) or } \\
\text { external pressure (e.g., demanding } \\
\text { expectations) }\end{array}$ & $\begin{array}{l}\text { Attempting to avoid doing worse than } \\
\text { before out of internal pressure (e.g., } \\
\text { guilt, ego-concerns) or external } \\
\text { pressure (e.g., demanding } \\
\text { expectations) }\end{array}$ & $\begin{array}{l}\text { Attempting to do avoid doing worse } \\
\text { than others out of internal pressure } \\
\text { (e.g., guilt, ego-concerns) or external } \\
\text { pressure (e.g., demanding } \\
\text { expectations) }\end{array}$ \\
\hline
\end{tabular}


Figure 4

Graphical Presentation of the Proposed Model Combining the "What" and "Why" of Personal Achievement Goal Pursuit

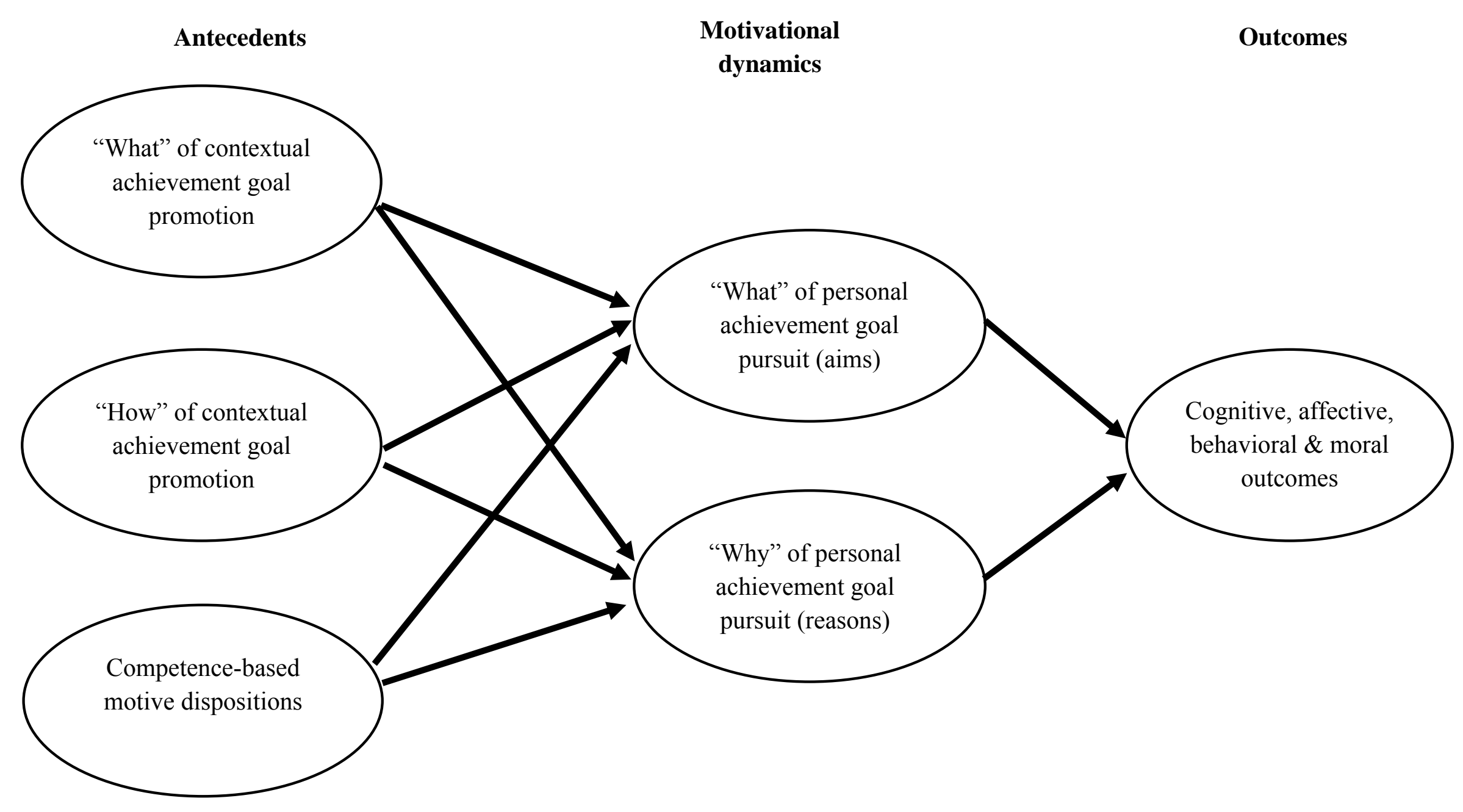

